\title{
Progress and Challenges of Mercury-Free Catalysis for Acetylene Hydrochlorination
}

\author{
Yanxia Liu ${ }^{1,2,3}$, Lin Zhao ${ }^{1}$, Yagang Zhang ${ }^{1,2,3, * \mathbb{D}}$, Letao Zhang ${ }^{3}$ and Xingjie Zan ${ }^{3}$ \\ 1 School of Materials and Energy, University of Electronic Science and Technology of China, Chengdu 611731, \\ China; liuyanxia@ms.xjb.ac.cn (Y.L.); zhaolin316@uestc.edu.cn (L.Z.) \\ 2 Department of Chemical and Environmental Engineering, Xinjiang Institute of Engineering, Urumqi 830026, China \\ 3 Xinjiang Technical Institute of Physics and Chemistry, Chinese Academy of Sciences, Urumqi 830011, China; \\ zhanglt@ms.xjb.ac.cn (L.Z.); zanxj@ms.xjb.ac.cn (X.Z.) \\ * Correspondence: ygzhang@uestc.edu.cn; Tel.: +86-28-61831516
}

Received: 9 September 2020; Accepted: 15 October 2020; Published: 20 October 2020

check for updates

\begin{abstract}
Activated carbon-supported $\mathrm{HgCl}_{2}$ catalyst has been used widely in acetylene hydrochlorination in the chlor-alkali chemical industry. However, $\mathrm{HgCl}_{2}$ is an extremely toxic pollutant. It is not only harmful to human health but also pollutes the environment. Therefore, the design and synthesis of mercury-free and environmentally benign catalysts with high activity has become an urgent need for vinyl chloride monomer (VCM) production. This review summarizes research progress on the design and development of mercury-free catalysts for acetylene hydrochlorination. Three types of catalysts for acetylene hydrochlorination in the chlor-alkali chemical industry are discussed. These catalysts are a noble metal catalyst, non-noble metal catalyst, and non-metallic catalyst. This review serves as a guide in terms of the catalyst design, properties, and catalytic mechanism of mercury-free catalyst for the acetylene hydrochlorination of VCM. The key problems and issues are discussed, and future trends are envisioned.
\end{abstract}

Keywords: vinyl chloride monomer; acetylene hydrochlorination; mercury-free catalysts; noble metal catalyst; non-noble metal catalyst; non-metallic catalysts

\section{Introduction}

Polyvinyl chloride (PVC) is one of the most important general purpose plastics. It is widely used in daily necessities and industrial application. It has the advantages of cheap and affordable features while also having superior comprehensive performance [1]. PVC is used in building materials, floor leather, packing materials, wires and cables, commodities, and other aspects [2]. In 2016, the global demand for PVC exceeded 45 million tons, among which China's PVC production exceeded 23 million tons, making it the world's largest producer and consumer of PVC [1]. PVC is a polymer made from vinyl chloride monomer (VCM) through the free radical polymerization mechanism. At present, the synthesis of VCM is mainly divided into three kinds: Ethane oxychlorination, ethylene oxychlorination, and acetylene hydrochlorination, respectively. Ethane oxychlorination started with natural gas resources, which is a new clean production process [1]. The lack of catalyst with good performance, especially high selectivity, is one of the main limiting factors restricting the method [3]. Ethylene oxychlorination is an environmentally benign process that depends on petroleum fossil fuels. Acetylene hydrochlorination is an important alternative process for the production of VCM in the coal-rich areas and the country [4-6]. In recent years, the increasing price of crude oil has highlighted the economic advantages of acetylene hydrochlorination. In the reaction of acetylene 
hydrochlorination to VCM, the atomic utilization of reactants is $100 \%$ [1]. The reaction process is as follows:

$$
\begin{gathered}
\mathrm{CaO}+3 \mathrm{C} \rightarrow \mathrm{CaC}_{2}+\mathrm{CO} \\
\mathrm{CaC}_{2}+2 \mathrm{H}_{2} \mathrm{O} \rightarrow \mathrm{CH} \equiv \mathrm{CH}+\mathrm{Ca}(\mathrm{OH})_{2} \\
\mathrm{CH} \equiv \mathrm{CH}+\mathrm{HCl} \rightarrow \mathrm{CH}_{2}=\mathrm{CHCl}
\end{gathered}
$$

This reaction is exothermic with high selectivity, and the optimum reaction temperature is 170-180 ${ }^{\circ} \mathrm{C}$ [6]. For more than 60 years, almost all the catalysts used in this process in industry are mercury-containing catalysts, with the dosage of $\mathrm{HgCl}_{2}$ ranging from $5 \mathrm{wt} \%$ to $12 \mathrm{wt} \%$ [7]. However, $\mathrm{Hg}$ catalysts have several disadvantages. $\mathrm{HgCl}_{2}$ is a linear triatomic aggregate, which is easily sublimed during the hydrochlorination reaction. The life cycle of the catalyst is correlated to the amount of $\mathrm{HgCl}_{2}$ catalyst loaded on the support [8]. During the acetylene hydrochlorination reaction, high temperature $\left(180-220^{\circ} \mathrm{C}\right)$ and pressure induces the desorption and sublimation of the $\mathrm{HgCl}_{2}$. This not only causes a loss of $\mathrm{HgCl}_{2}$ from the support but also poses a serious pollution problem [7]. The high temperature generates hot spots that aggravate the situation, resulting in a significant amount of mercury loss [9]. As a cumulative toxin, $\mathrm{HgCl}_{2}$ is extremely toxic and harmful. Therefore, the loss of $\mathrm{HgCl}_{2}$ will not only lead to the deactivation of the catalysts but also cause serious environmental issues [10]. Although efforts have been taken to recycle the losing mercury, about $25 \%$ of it is released directly into the environment [11]. In order to solve this issue, worldwide, the Minamata Convention has agreed on controlling the mercury emission reduction act in 2013 by the United Nations Environment Protection Committee. The agreement came into effect on 16th August 2017.

In order to reduce the mercury compounds released from the hydrochlorination process, it is urgent and of paramount importance to develop environmentally friendly green mercury-free catalysts as substitutes. In this review, we discuss the recent research progress and challenges for mercury-free catalysts (Scheme 1). Perspectives and future trends for the development of greener and cleaner processes for VCM production with mercury-free catalysts are also discussed.

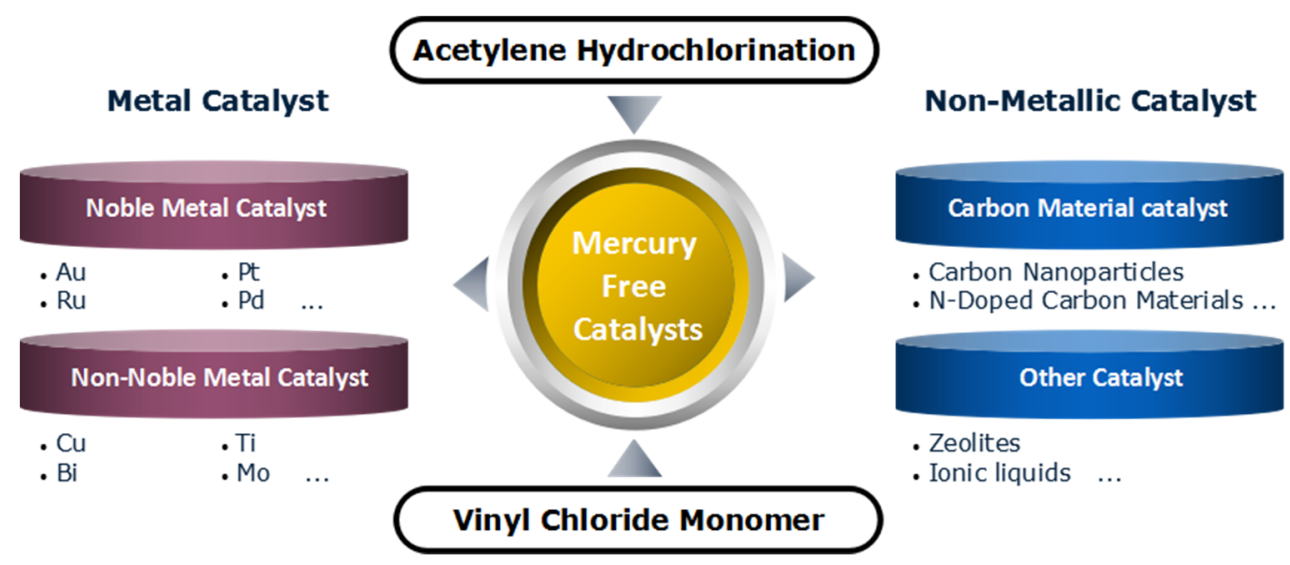

Scheme 1. Mercury-free catalysts for acetylene hydrochlorination.

\section{Noble Metal Catalysts}

The research of acetylene hydrochlorination catalysts supported by metal has been going on for 50 years. Smith et al. reported compound metal $(\mathrm{Hg}, \mathrm{Bi}, \mathrm{Ni}, \mathrm{Zn}, \mathrm{Cd}, \mathrm{Cu}, \mathrm{Mn}$, and $\mathrm{Ca}$ ) catalysts supported on silica for acetylene hydrochlorination in 1968 [12]. In 1975, Shinoda prepared metal chloride catalysts with activated carbon as the support. In their work, the results revealed that the catalytic activity of metal chloride was well correlated to the electron affinity of metal cations (Figure 1) [13]. One class of metal cations had its catalytic activity increase with the increase of electron affinity. Meanwhile, another class 
of metal cations demonstrated the opposite trend, and this was considered to be due to cations forming complexes with $\mathrm{HCl}$ of the type $\mathrm{H}_{m}\left[\mathrm{MCl}_{n}+\mathrm{m}\right]$, which were Friedel-Crafts-type catalysts [14].

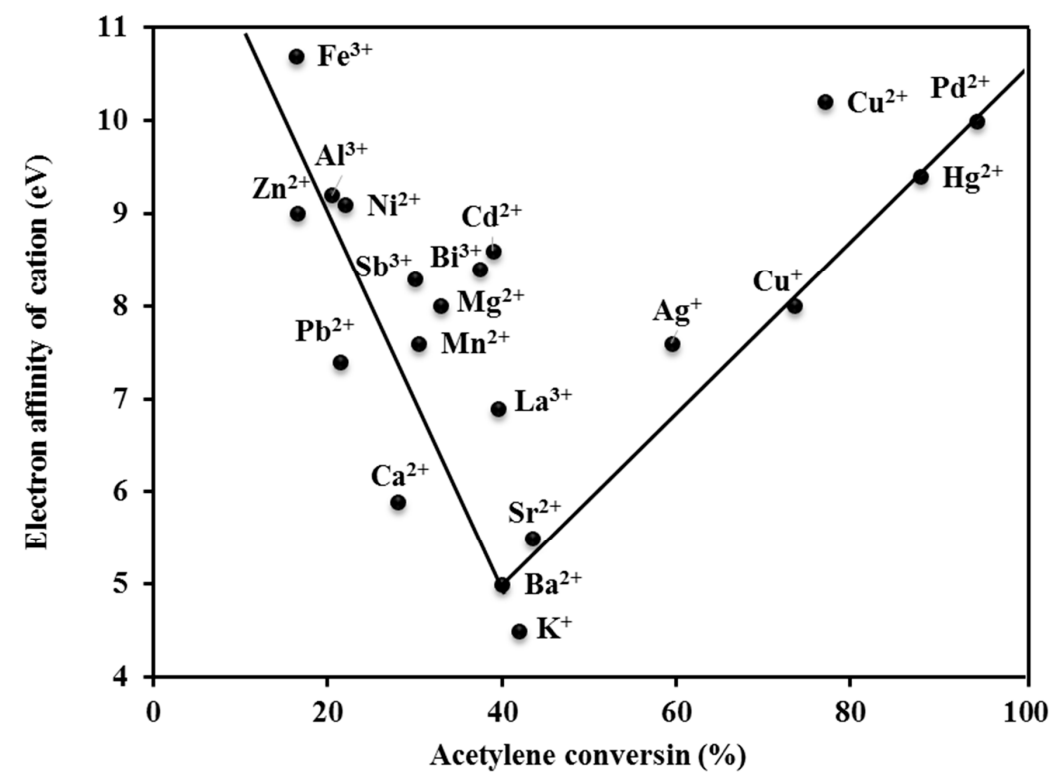

Figure 1. The relationship between acetylene hydrochlorination activity of metal chlorides and electron affinities of metal cations. Adopted from Ref [13].

In 1985, Hutchings evaluated a series of supported metal chloride catalysts analyzed by Shinoda and made different attribution associations. Hutchings reported that the interaction between acetylene and metal chloride may involve the transfer of more than one electron. Therefore, the standard reduction potential was considered to be a more appropriate parameter to correlate catalytic activity. Except for a few metals such as $\mathrm{K}, \mathrm{Ba}, \mathrm{Mg}$, and $\mathrm{La}$, most of the metals showed a positive correlation between its activity and the standard electrodes potential in acetylene hydrochlorination (Figure 2) [14]. The proposed correlation has certain guiding significance to the research of acetylene hydrochlorination. Based on these results, a large number of studies on mercury-free catalysts are conducted on noble metals.

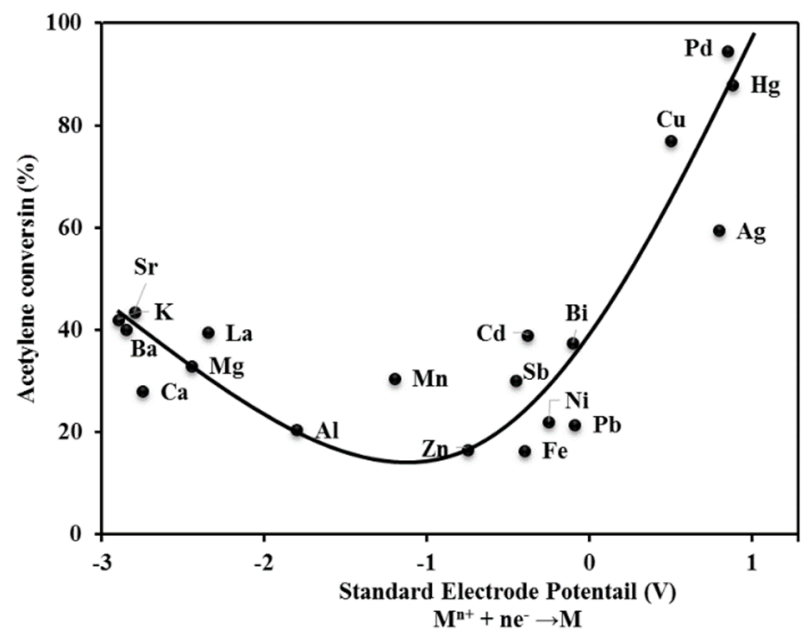

Figure 2. The relationship between acetylene hydrochlorination activity of metal chlorides and standard reduction potential [14]. 


\subsection{Au Catalysts}

In 1985, Hutchings predicted that Au might have good activity for acetylene hydrochlorination [14]. The prediction was verified in the article reported in 1988 [8]. Figure 3 further confirmed the correlation with the standard electrode potential. Since then, studies on supported Au catalysts have been increasing. The earliest method for preparing Au catalysts was to dissolve the gold of high purity in aqua regia and on the carbon support, which could minimize the introduction of impurities and avoid the adverse effects of impurities on the catalysts $[8,15,16]$.

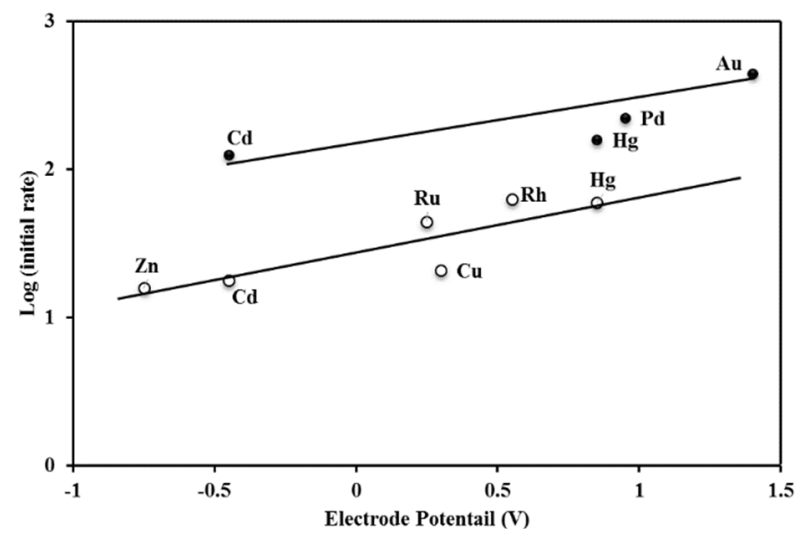

Figure 3. The correlation between catalytic activity and standard electrode potential of metal cations in acetylene hydrochlorination [16].

\subsection{1. $\mathrm{Au}^{\mathrm{n}+}$ Catalysts}

Most studies on the catalytic mechanism of $\mathrm{Au}$ catalysts showed that the amount of $\mathrm{Au}^{3+}$ had a great correlation with the catalytic activity and was considered as the active species for acetylene hydrochlorination. For $\mathrm{Au}$ species, the order of catalytic activity was $\mathrm{Au}^{3+}>\mathrm{Au}^{+}>\mathrm{Au}^{0}$. Although it has also been reported that $\mathrm{AuCl}$ can be used as a catalytic active species [17], due to the poor stability of $\mathrm{AuCl}$ in aqueous solution and reaction conditions, a disproportionation reaction occurs, resulting in the formation of $\mathrm{AuCl}_{3}$ and elemental $\mathrm{Au}$ :

$$
3 \mathrm{AuCl} \rightarrow \mathrm{AuCl}_{3}+2 \mathrm{Au}
$$

Since the equilibrium constant of the reaction is very large ( $10^{10}$ orders of magnitude), it can be considered that there is almost no free $\mathrm{Au}^{+}$in aqueous solution, and it is difficult to prepare supported $\mathrm{AuCl}$ catalysts using conventional preparation methods. Therefore, $\mathrm{Au}^{3+}$ catalyst is the most studied and applied catalyst.

Conte et al. demonstrated that exposure to $\mathrm{HCl}$ before reaction led to enhanced catalyst activity, whereas exposure to acetylene resulted in a decrease of catalyst activity [5]. It was proposed that the catalytic activity of $\mathrm{Au}^{3+}$ could be explained by two possible mechanisms: (a) a nucleophilic electrophilic interaction between the $\mathrm{Au}^{3+}$ center and a triple bond of acetylene through $\pi$-coordination; and $(\mathrm{b})$ the acidic protons of the terminal alkyne facilitated $\sigma$-coordination $[5,18,19]$. The reaction mechanism of $\mathrm{HAuCl}_{4}\left(\mathrm{Au}^{3+}\right)$ as the active species was proposed in Figure 4 [5]. This mechanism involved the presence of both acetylene and $\mathrm{HCl}$ for a six-member ring. In the six-member ring, the alkyne axially coordinated to the $\mathrm{Au}^{3+}$ center. Density functional theory (DFT) calculations implied that it was unlikely that the simultaneous coordination of acetylene and $\mathrm{HCl}$ to the $\mathrm{Au}^{3+}$ center would occur. The transition state for $\mathrm{HCl}$ addition to the $\pi$-complex of acetylene with $\mathrm{AuCl}_{3}$ by calculation predicted that the stereochemistry of $\mathrm{Cl}$ addition was controlled by a hydrogen bond between $\mathrm{HCl}$ and a $\mathrm{Cl}$ ligand of $\mathrm{Au}$. The anti-addition of $\mathrm{HCl}$ observed experimentally was a consequence of a sequential addition of $\mathrm{Cl}$ and $\mathrm{H}$ to the acetylene $[5,6,20-23]$. 


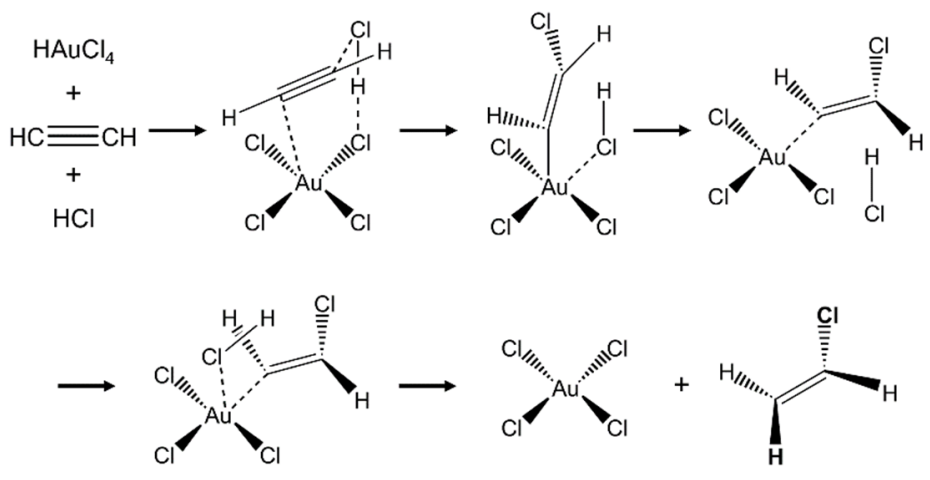

Figure 4. Acetylene hydrochlorination model of $\mathrm{Au}^{3+}$ catalyst [5].

The preparation method of catalysts has an important influence on its performance and activity. Conte et al. showed that Au could be highly dispersed on support with acid as the solvent [24]. They found that aqua regia was the most effective solvent for preparing the catalyst, while catalysts prepared using $\mathrm{HCl}$ or $\mathrm{HNO}_{3}$ individually were less active. The superior activity of the catalyst prepared in aqua regia was proposed to be a combination of the oxidizing effect of $\mathrm{HNO}_{3}$ and the nucleating effect of $\mathrm{HCl}$. Both of these are helpful to promote the high dispersion of $\mathrm{Au}[5,7,25]$. Although aqua regia is an effective solvent, it is extremely corrosive and dangerous, causing negative impacts on the environment and threatening the safety of the process. In addition, there are many difficulties in the treatment, recovery, and disposal of the used aqua regia, so it is not suitable for industrial application $[26,27]$. Therefore, researchers began to develop a similar activation protocol that could be realized by using other environmentally friendly solvents.

The general mechanism of catalyst deactivation is the reduction of $\mathrm{Au}^{3+}$ to $\mathrm{Au}^{0}$. It is urgent to improve the stability of active $\mathrm{Au}^{3+}$ species and extend the service life of the catalyst. Zhao et al. reported that organic aqua regia (OAR, 1:10 $\mathrm{SOCl}_{2}$ : DMF) could be used as a substituent for conventional aqua regia to activate $\mathrm{Au} / \mathrm{AC}$ catalyst with $\mathrm{Au}^{3+}$ as the active center. OAR could promote $\mathrm{Au}$ oxidation and help achieve high disparity. The content of $\mathrm{Au}^{3+}$ species in $\mathrm{Au}\left(\mathrm{H}_{2} \mathrm{O}\right) / \mathrm{AC}(\mathrm{OAR})$ was greater than that in the $\mathrm{Au}$ (aqua regia)/AC sample, indicating that OAR treatment could partially promote the oxidation of $\mathrm{Au}^{0}$ into $\mathrm{Au}^{3+}$. Residual $\mathrm{S}$ and $\mathrm{N}$ stabilized the $\mathrm{Au}^{3+}$ species and generated a more thermally stable catalyst by forming $\mathrm{Au}-\mathrm{S}$ complexes, increasing the electron density of the $\mathrm{Au}$ center through electron transfer, enhancing the reduction temperature of $\mathrm{Au}^{3+}$, and promoting the effective adsorption of $\mathrm{HCl}$ on the Au catalyst (Figure 5) [28].

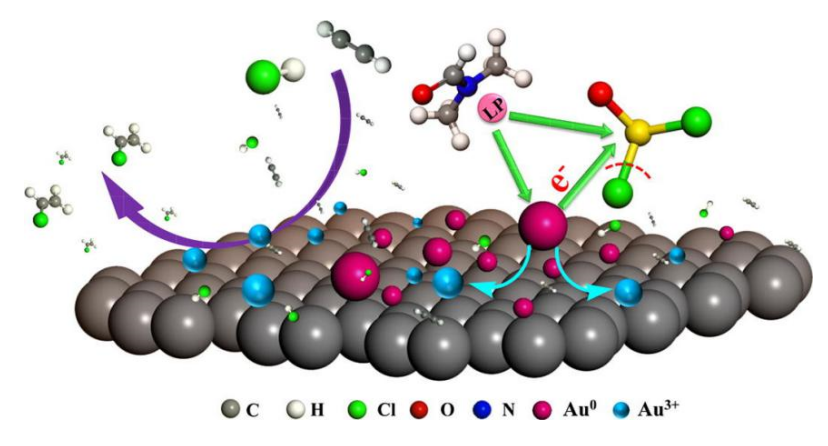

Figure 5. Au catalysts prepared by organic aqua regia [28].

Huang et al. studied the effect of the 1,10-phenanthroline ligand on Au catalyst performance. With an appropriate ligand, the $\left[\mathrm{AuCl}_{2}\right.$ (phen) $] \mathrm{Cl}$ catalyst achieved excellent acetylene conversion $(90 \%)$ after $40 \mathrm{~h}$ of operation. The enhanced catalytic stability was attributed to the presence of 
the phen ligand; electron transfer from the phen species to the $\mathrm{Au}^{3+}$ center increased the $\mathrm{Au}^{3+}$ electron density, which inhibited the active $\mathrm{Au}^{3+}$ component deactivation [29].

Chao et al. prepared Au catalysts using activated carbon pretreated at different temperatures. It was shown that thermal treatments can change the surface functional groups on activated carbon. Ketone, lactone, and carbonyl tended to anchor $\mathrm{Au}$ on the surface with a good dispersion state. The phenolic and alcohol groups can easily reduce $\mathrm{Au}^{3+}$ to $\mathrm{Au}^{0}$, which is not active for the reaction. Surface functional groups may be a constituent part of the active sites adsorbing and activating acetylene. This indicated that both $\mathrm{Au}^{3+}$ and the surface functional groups work in synergy as the active sites [30].

\subsection{2. $\mathrm{Au}^{0}$ Catalysts}

There are some studies that have reported that $\mathrm{Au}^{0}$ is the active center of $\mathrm{Au}$ catalysts. The catalytic efficiency of $\mathrm{Au}^{0}$ catalysts is closely related with the dispersion degree of Au nanoparticles (Au NPs). Some researchers have demonstrated that the various edges or defects of multiple-twinned or polycrystalline particles formed on the surface of the Au NPs catalyst have high surface stress and are easily broken to reduce their surface energy, thus providing active sites for acetylene hydrochlorination.

Zhang et al. revealed that $\mathrm{Au}^{0}$ catalyst activity was strongly associated with the properties of the used solvent. It was found that the catalyst's activity increased with the decreased polarity of solvents. Compared to polar solvents such as water and aqua regia, less polar solvent alcohols would influence the formation of crystallization of Au NPs. The mean particle size in Au-x/AC $(\mathrm{x}=$ alcohol) catalysts was determined to be $3.9-4.7 \mathrm{~nm}$ and showed peculiar characteristic of spherical $\mathrm{Au}$ NPs, demonstrating good dispersity on the catalysts. Au NPs exhibited good catalytic activity. Polycrystalline particles formed with various edges or defects could act as active sites. Weakly polar alcohols facilitated the interfacial interaction between the support and $\mathrm{Au}^{0}$ species, made the active species highly dispersed, and anchored and inhibited the agglomeration and loss during the reaction. Moreover, the interaction also enhanced catalytic activity by increasing the adsorption capacity on the catalyst's surface [31].

Different preparation methods including ultrasonic, microwave, and incipient wetness impregnation were also studied and compared for acetylene hydrochlorination. Wittanadecha et al. investigated the catalytic performance of $\mathrm{Au}^{0}$ catalysts using different preparation routes. It was found that the ultrasonic-assisted method improved the dispersion of the active component and increased the pore volume and aperture of the support. Noticeably and interestingly, only the initial activity of the catalyst was affected with different pretreatment processes, while the overall catalyst activity was almost unaffected. They suspected that the active Au species is $\mathrm{Au}^{0}$. The $\mathrm{Cl}$-containing substance is chemically adsorbed and reacts with acetylene to form a VCM [32].

Tian et al. prepared an $\mathrm{Au}$ catalyst (MIV-1Au/C1) with significantly increased activity . The catalysts were synthesized using mixed solvents and vacuum drying instead of the traditional impregnation method. $\mathrm{Au}^{0}$ with a mean size of $5.2 \mathrm{~nm}$ was in the face-centered cubic form and was the only active species of MIV-1Au/C1 at the initial/highest point of the testing. The active species of $\mathrm{Au}^{0}$ could be oxidized to $\mathrm{Au}^{3+}$ and became deactivated during the acetylene hydrochlorination reaction. The particle size of Au NPs prepared by this method was much smaller than that by the immersion method [33].

\subsubsection{Modification of Au Catalysts}

Efforts were devoted to improving the efficiency and enhancing the stability of active sites of Au catalysts. Adding synergistic metals, forming ligand coordination, and support modification have been attempted to solve the problems of catalysts deactivation, coke deposits, and Au particles aggregation (Scheme 2). 


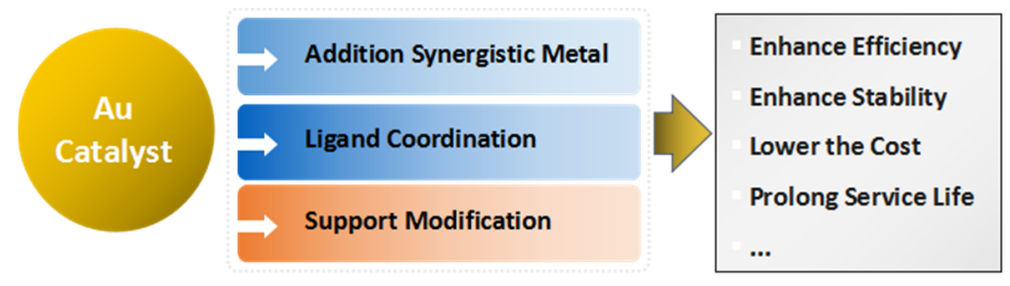

Scheme 2. Modification of Au catalysts.

\section{Addition Synergistic Metal}

$\mathrm{Au}^{3+}$ catalysts suffer from poor stability both during preparation and application. One way to solve this problem is to dope Au with other elements so that the electronic state of the active sites can be tuned. In 2008, Conte et al. studied the effect of different metal additives on the catalytic performance of $\mathrm{Au}^{3+}$ catalysts. The metals used include $\mathrm{Pd}, \mathrm{Pt}, \mathrm{Ir}, \mathrm{Rh}$, and $\mathrm{Ru}$. The results showed that dispersed pure Au was actually the most active one for acetylene hydrochlorination in a long run. The addition of other metals did not improve the catalytic reactivity [34]. However, in recent years, studies have shown the opposite observations and conclusions when $\mathrm{Au}$ was doped with other elements, such as $\mathrm{La}, \mathrm{Cu}, \mathrm{Bi}, \mathrm{Sn}$, $\mathrm{Ce}, \mathrm{Sr}$, etc. to modified Au catalysts, which may have higher catalytic stability due to synergy effects [35]. On the one hand, the loading capacity of Au can be reduced, which led to reducing the cost of catalyst by adding metal additives. On the other hand, these metal additives provide electrons to $\mathrm{Au}^{3+}$, absorb more oxidizing $\mathrm{HCl}$, and slow down the reduction of $\mathrm{Au}^{3+}$. Table 1 lists some AuM catalysts prepared with $\mathrm{HAuCl}_{4}$ in collaboration with other synergistic metal precursors. The results show that the addition of metal additives can improve the dispersion of $\mathrm{Au}^{3+}$, stabilize the chemical valence of the active center, enhance the electron cloud density of the $\mathrm{Au}^{3+}$ active center, inhibit carbon deposition, and finally improve the catalytic efficiency for acetylene hydrochlorination.

Table 1. Performance of AuM catalysts for acetylene hydrochlorination.

\begin{tabular}{|c|c|c|c|c|c|c|c|c|}
\hline Year & Catalyst & Synergistic Metal & $\mathrm{Au}(w \mathrm{t} \%)$ & $\begin{array}{c}\text { GHSV } \\
\left(h^{-1}\right)\end{array}$ & $\begin{array}{l}\text { Temp } \\
\left({ }^{\circ} \mathrm{C}\right)\end{array}$ & $\begin{array}{l}\text { Acetylene } \\
\text { Conv. (\%) }\end{array}$ & $\begin{array}{l}\text { Running } \\
\text { Time (h) }\end{array}$ & Ref. \\
\hline 2019 & $\mathrm{AuCe}$ & $\mathrm{CeO}_{2}$ & 0.1 & 60 & 180 & 99.9 & 70 & {$[4]$} \\
\hline 2016 & $\mathrm{AuCe}$ & $\mathrm{CeO}_{2}$ & 1.0 & 852 & 180 & 98.4 & 20 & [36] \\
\hline 2017 & AuY & $\mathrm{YCl}_{3}$ & 1.0 & 800 & 180 & 87.8 & 10 & [37] \\
\hline 2016 & AuSn & $\mathrm{SnCl}_{2}$ & 0.9 & 720 & 170 & 95 & 48 & [38] \\
\hline 2017 & $\mathrm{AuCu}$ & $\mathrm{CuCl}_{2}$ & 0.1 & 740 & 180 & 98.5 & 500 & [39] \\
\hline 2016 & $\mathrm{AuCu}$ & $\mathrm{CuCl}_{2}$ & 0.1 & 120 & 150 & 97 & 4 & [40] \\
\hline 2015 & $\mathrm{AuCu}$ & $\mathrm{CuCl}_{2}$ & 0.25 & 120 & 150 & 97 & 2 & [41] \\
\hline 2017 & AuCuK & $\mathrm{CuCl}_{2} / \mathrm{KCl}$ & 0.2 & 40 & 165 & 89 & 1600 & [42] \\
\hline 2014 & $\mathrm{AuCoCu}$ & $\mathrm{Co}\left(\mathrm{NH}_{3}\right)_{6} \mathrm{Cl}_{3} / \mathrm{CuCl}_{2}$ & 1.0 & 720 & 150 & 99 & 5 & [43] \\
\hline 2018 & $\mathrm{AuSr}$ & $\mathrm{SrCl}_{2}$ & 1.0 & 1806 & 180 & 99.7 & 180 & [44] \\
\hline 2016 & AuSr & $\mathrm{SrCl}_{2}$ & 1.0 & 762 & 180 & 87.7 & 20 & [45] \\
\hline 2015 & $\mathrm{AuBa}$ & $\mathrm{BaCl}_{2}$ & 1.0 & 360 & 200 & 98.4 & 50 & [46] \\
\hline 2015 & $\mathrm{AuCs}$ & $\mathrm{CsCl}$ & 1.0 & 740 & 180 & 94 & 50 & [47] \\
\hline 2015 & $\mathrm{AuCs}$ & $\mathrm{CsCl}$ & 1.0 & 1480 & 180 & 90.1 & 50 & [48] \\
\hline 2015 & AuInCs & $\mathrm{CsCl} / \mathrm{InCl}_{3}$ & 1.0 & 1480 & 180 & 92.8 & 50 & [49] \\
\hline 2014 & AuBi & $\mathrm{BiCl}_{3}$ & 1.0 & 600 & 180 & 85 & 10 & [17] \\
\hline 2014 & $\mathrm{AuBi}$ & $\mathrm{BiCl}_{3}$ & 1.0 & 120 & 150 & 96 & 10 & [50] \\
\hline 2014 & AuTi & $\mathrm{TiO}_{2}$ & 1.0 & 870 & 180 & 92 & 10 & [51] \\
\hline 2014 & $\mathrm{AuNi}$ & $\mathrm{NiCl}_{2}$ & 1.5 & 900 & 170 & 95.4 & 46 & [52] \\
\hline 2013 & $\mathrm{AuCo}$ & $\mathrm{Co}\left(\mathrm{NH}_{3}\right)_{6} \mathrm{Cl}_{3}$ & 1.0 & 360 & 150 & 99.9 & 36 & [53] \\
\hline 2012 & AuLa & $\mathrm{LaCl}_{3}$ & 1.0 & 360 & 150 & 98 & 50 & [54] \\
\hline
\end{tabular}

\section{Ligand Coordination}

It is a common modification method to introduce suitable ligands to stabilize the high valence $\mathrm{Au}^{3+}$ in $\mathrm{Au}$ catalysts. Results showed that the activity and stability of the $\mathrm{Au}^{3+}$ catalyst could be 
significantly improved with the addition of chelating donors and $\mathrm{N}$-containing ligands. The donor groups include thiosulfate, thiocyanate, thiourea, and cyanides $[55,56]$. The catalyst complexes can be prepared by synthesizing complexes and then loading them on the support; or they can be formed by directly adding the precursor of the complexes to the $\mathrm{HAuCl}_{4}$ during the preparation process and then forming the Au complexes with catalytic activity in situ. Zhou et al. reported an Au catalyst with thiocyanate $(-\mathrm{SCN})$ donors with $0.25 \mathrm{wt} \%$ Au loading. The donor significantly decreased the electrode potential of $\mathrm{Au}^{3+}$ from 0.926 to $0.662 \mathrm{~V}$. Complexion prevented Au catalyst deactivation by increasing the reaction energy barrier [57]. Table 2 shows some Au catalysts prepared with different ligand precursors; $\mathrm{Au}^{3+}$ has high catalytic activity for acetylene hydrochlorination.

The catalytic activities of $\mathrm{Au}^{0}$ catalysts ( $\mathrm{Au} \mathrm{NPs}$ ) could be influenced by many factors. These factors include the Au cluster size and shape [58,59], the cluster charge $[60,61]$, the structure of the support material [62], and the ligand [63]. Recently, it was found that doped Au clusters can form distinctive structures and achieve enhanced properties. Zhao et al. proposed a mechanism for pristine $\mathrm{Au}_{7}$ and $\mathrm{Au}_{8}$ clusters catalysts and, on the Si-doped Au clusters, $\mathrm{Au}_{6} \mathrm{Si}$ and $\mathrm{Au}_{7} \mathrm{Si}$ based on DFT. The results showed that the reaction process of acetylene hydrochlorination catalyzed by $\mathrm{Au}^{0}$ involved two steps. In the first step, $\mathrm{HCl}$ disassociated and $\mathrm{Cl}$ was added, which was followed by $\mathrm{H}$ addition through the transfer of protons from the Au cluster to acetylene chloride. Doping can not only change the size and shape of Au clusters but also improve the efficiency for acetylene hydrochlorination [64].

Table 2. Au catalysts prepared with different ligand precursors.

\begin{tabular}{|c|c|c|c|c|c|c|c|c|}
\hline Year & Catalyst & Ligand & $\mathrm{Au}(\mathrm{wt} \%)$ & $\begin{array}{c}\text { GHSV } \\
\left(h^{-1}\right)\end{array}$ & $\begin{array}{c}\text { Temp } \\
\left({ }^{\circ} \mathrm{C}\right)\end{array}$ & $\begin{array}{l}\text { Acetylene } \\
\text { Conv. (\%) }\end{array}$ & $\begin{array}{l}\text { Running } \\
\text { Time (h) }\end{array}$ & Ref. \\
\hline 2016 & $\mathrm{Au} / \mathrm{TCCA}$ & Trichloroisocyanuric acid & 0.2 & 90 & 180 & 98 & 24 & [65] \\
\hline 2015 & $\mathrm{Au}\left(\mathrm{CS}\left(\mathrm{NH}_{2}\right)_{2}\right.$ & Thiourea & 0.1 & 500 & 130 & 95 & 24 & [8] \\
\hline 2015 & $\mathrm{Au} / \mathrm{SCN}$ & $\mathrm{KSCN}$ & 0.25 & 1200 & 180 & 99 & 10 & [57] \\
\hline 2014 & {$\left[\mathrm{AuCl}_{2}\right.$ (phen)]Cl } & 1,10-phenanthroline & 0.49 & 603 & 180 & 90 & 40 & [29] \\
\hline
\end{tabular}

\section{Support Modification}

Support is an important component of catalysts and has a great influence on the performance of $\mathrm{Au}$ catalysts. Choosing an appropriate support material is crucial under rigorous reaction conditions. The catalysts need to be robust and stable enough at high temperature. Support is also critical in view of stabilizing the highly dispersed metal chloride and preventing the agglomeration of active components [7]. For supported metal catalysts, support modification is common to increase the guest-host interaction. One example is to dope carbon support with heteroatoms such as N, B, and P.

The catalytic performance of supported metal catalysts is greatly dependent on the properties of the support. Carbon materials are recognized as ideal supports because of their large surface area and good electrical conductivity. Chen et al. observed that mesoporous carbon supports could increase the activity of $\mathrm{Au}^{3+}$ catalysts prepared with an $\mathrm{HAuCl}_{4}$ precursor. The pore size of supports was important because large pore sizes allowed rapid diffusion and suppressed coke formation [67]. Jia et al. reported that the addition of a $\mathrm{B}$ species was favorable for the stabilization of active $\mathrm{Au}^{3+}$ species and the inhibition of a transition from $\mathrm{Au}^{3+}$ to $\mathrm{Au}^{0}$. In addition, the $\mathrm{B}$ species also inhibited carbon deposition and catalyst sintering during the reaction [68].

Zhang et al. reported several $\mathrm{Au}$-bimetallic catalysts for acetylene hydrochlorination. The catalysts were prepared with $\mathrm{HAuCl}_{4}$ and $\mathrm{LaCl}_{3}$ precursors on different supports. The results indicated that compared with $\mathrm{SiO}_{2}$ and $\mathrm{TiO}_{2}$, coconut shell activated carbon and pitch-based spherical activated carbon were desirable. These supports showed more developed pore structures and had larger specificity. Pitch-based spherical activated carbon was found to be more desirable for acetylene hydrochlorination than coconut shell activated carbon because it had a higher $\mathrm{N}$ content. Au particles' aggregation and the loss of $\mathrm{Au}^{3+}$ would decrease the catalyst activity. Furthermore, the valence change of $\mathrm{Au}^{3+}$ and 
carbon deposition were also responsible for catalyst deactivation. The addition of La to Au can help stabilize $\mathrm{Au}^{3+}$ by inhibiting the valence change and carbon deposition [54].

$\mathrm{N}$-doped carbon is one of the hot topics in support modification. $\mathrm{N}$-doped carbon material as a non-metal catalyst has shown promising properties for acetylene hydrochlorination $[69,70]$. The introduction of $\mathrm{N}$ species changed the electronic structure of the adjacent carbon atoms so to adsorb $\mathrm{HCl}$ or acetylene easily, thereby enhancing the catalytic activity of carbon-supported catalysts. Dai et al. reported $\mathrm{AuCl}_{3} / \mathrm{PPy}$-multiwall carbon nanotubes (MWCNTs) with enhanced catalytic performance compared with $\mathrm{AuCl}_{3} / \mathrm{MWCNTs}$. This was attributed to electron transfer from polypyrrole to the $\mathrm{Au}^{3+}$ center, which facilitated the adsorption of $\mathrm{HCl}$ (Figure 6) [66]. Zhao et al. incorporated $\mathrm{N}$-containing functional groups into carbon support by the post-modification of activated carbon with urea. The results showed that electron transfer from $\mathrm{N}$ atoms to the $\mathrm{Au}^{3+}$ center accelerated the adsorption of $\mathrm{HCl}$ by increasing the electron density of $\mathrm{Au}^{3+}$ [71].
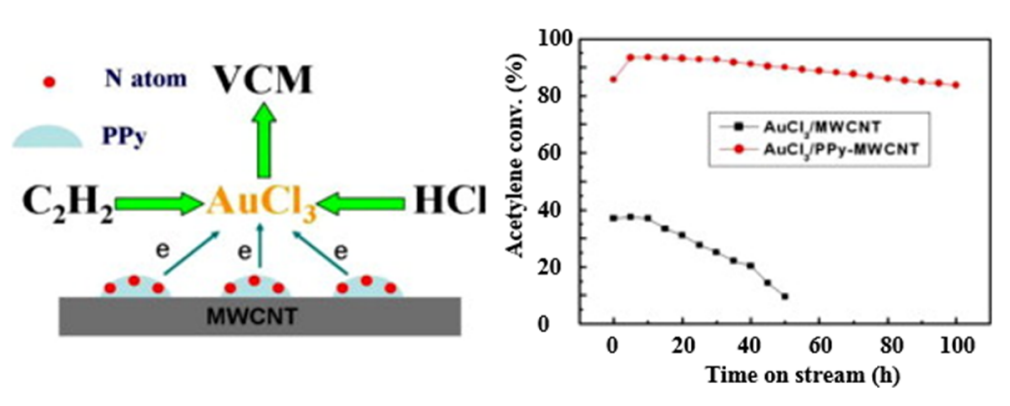

Figure 6. $\mathrm{AuCl}_{3} / \mathrm{PPy}$-multiwall carbon nanotube (MWCNT) catalyst for acetylene hydrochlorination [66].

ILs (Ionic liquids) are also used to stabilize $\mathrm{Au}^{3+}$ catalysts. Zhao et al. obtained $\mathrm{Au}^{3+}$ complexes, $\mathrm{Au}$ ILs (1-propyl-3-methylimidazolium tetrachloroaurate ([Prmim] $\left.\mathrm{AuCl}_{4}\right)$ ). The $\mathrm{Au}^{3+}-\mathrm{IL} / \mathrm{C}$ catalyst showed higher activity and stability than IL-free $\mathrm{Au} / \mathrm{C}$ [72]. Zhao et al. reported that the reduced $\mathrm{Au}^{0}$ could be regenerated in situ to $\mathrm{Au}^{3+}$ by $\mathrm{CuCl}_{2}$ and further stabilized by the electron transfer from $\mathrm{Cu}^{2+}$ to these active species. The $\mathrm{Au}^{3+}-\mathrm{Cu}^{2+}-\mathrm{IL} / \mathrm{C}$ catalyst demonstrated excellent activity. With this catalyst, over $99.8 \%$ selectivity was achieved for the VCM product (Figure 7) [39].

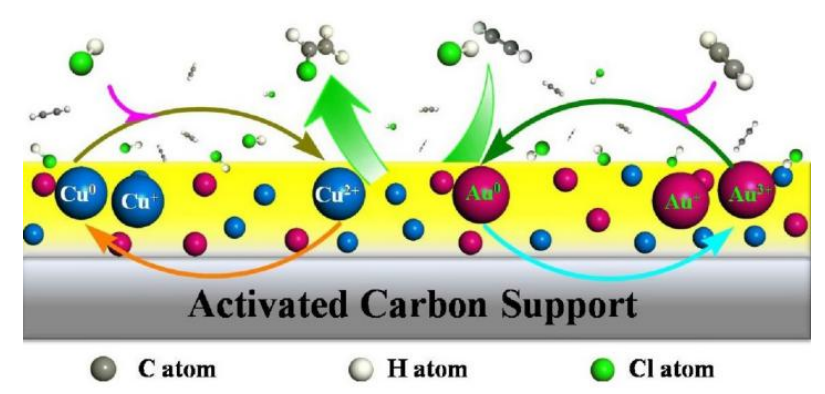

Figure 7. $\mathrm{Au}^{3+}-\mathrm{Cu}^{2+}-\mathrm{IL} / \mathrm{C}$ catalyst for acetylene hydrochlorination [39]. IL: Ionic liquid.

Modification of the support can also improve the activity of the $\mathrm{Au}^{0}$ catalyst. Tian et al. found that amorphous silica could be dispersed on the carbon surface uniformly as spherical particles. Silica deposition achieved a better distribution of Au NPs, which improved the catalytic activity of the $\mathrm{Au}^{0}$ catalyst, although the surface area was decreased [73]. Dai et al. found that a mesoporous carbon nitride material can control the Au NPs sizes and was active for acetylene hydrochlorination [74]. Kang et al. reported that graphene substrate can improve the adsorption of $\mathrm{HCl}$ and $\mathrm{C}_{2} \mathrm{H}_{2}$, and $\mathrm{N}$-doping significantly weakened the interaction with the $\mathrm{Au}_{3}$ cluster for acetylene hydrochlorination [75]. Gong et al. reported that adding the heteroatom $\mathrm{N}$ to Au embedded in graphene $(\mathrm{AuG})$ could reduce the reaction activation energy based on DFT calculations (Figure 8). 
With N-doping in AuG-SAC, the adsorption ability was increased, and the interaction between the starting materials $\mathrm{HCl}$ and acetylene was significantly enhanced. The energy band gap $(\Delta \mathrm{Eg})$ between the Highest Occupied Molecular Orbital (HOMO) of AuG- $\mathrm{N}_{\mathrm{n}}$-acetylene and the Lowest Unoccupied Molecular Orbital (LUMO) of the HCl, N-doped AuG-SACs decreased. Overall, this could reduce the activation energy of acetylene hydrochlorination [76].

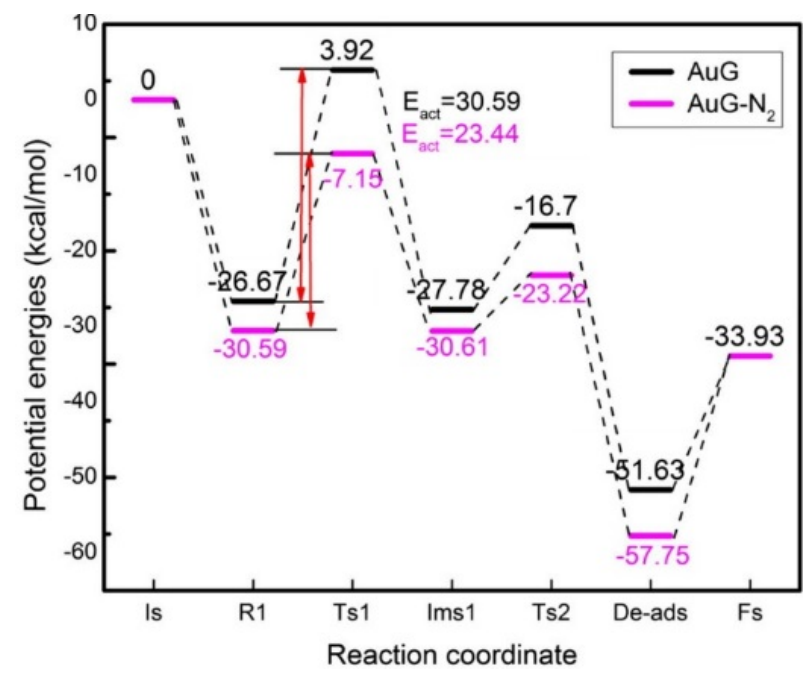

Figure 8. Energy diagrams of acetylene hydrochlorination on $A u G$ and AuG- $\mathrm{N}_{4}$ spheric active carbons (SACs) [76].

\subsubsection{Deactivation and Regeneration of Au Catalysts}

In 1988, Hutchings et al. investigated the reactivation by treatment of used catalysts in situ in the reactor with $\mathrm{HCl}$. This treatment was applied to $\mathrm{Au}^{3+}$ and $\mathrm{Hg}^{2+}$ catalysts (Figure 9). The results indicated that the $\mathrm{Hg}$ catalyst cannot be reactivated, and $25 \%$ of the mercury had been lost from the catalyst. However, the activity of $\mathrm{Au}$ catalysts treated with $\mathrm{HCl}$ can be restored to the initial activity and the Au content of the deactivated catalyst did not decrease [16].

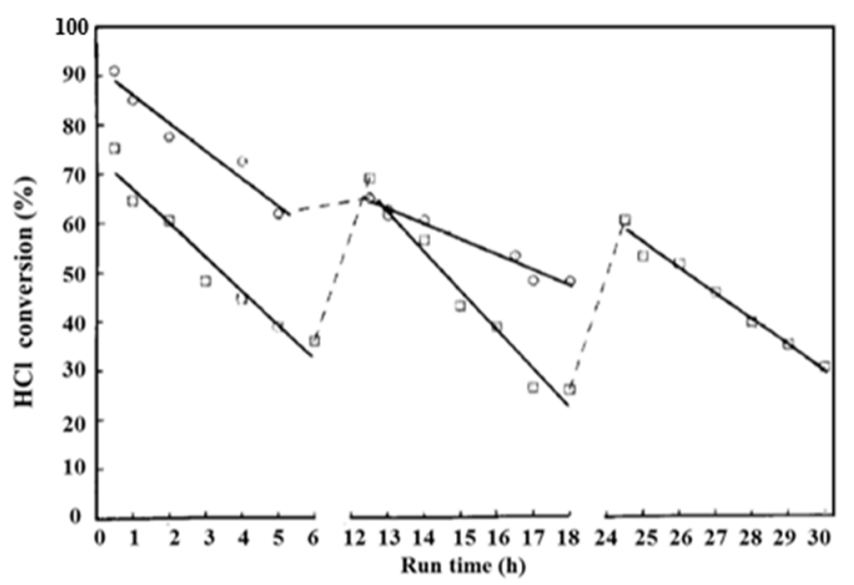

Figure 9. Effect of reactivation of catalyst with $\mathrm{HCl}$ treatment; $\bigcirc \mathrm{HgCl}_{2} / \mathrm{C}, 9 \% \mathrm{Hg} ; \square \mathrm{HAuCl}_{4} / \mathrm{C}$, $1.9 \% \mathrm{Au} ;(-) \mathrm{HCl}$ treatment [16].

The deactivation of a supported $\mathrm{Au}$ catalyst with $\mathrm{Au}^{3+}$ as the active species can be attributed to the following factors: the reduction, aggregation of the active particles of the Au catalyst, and the carbon deposition on the catalyst surface area, which may occur simultaneously [9,77]. Nkosi et al. reported that at low temperature $\left(60-100^{\circ} \mathrm{C}\right)$, carbon deposition led to the deactivation of the Au catalyst. At higher 
temperatures $\left(120-180^{\circ} \mathrm{C}\right)$, the active component $\mathrm{Au}^{3+} / \mathrm{Au}^{+}$was reduced to $\mathrm{Au}^{0}$, resulting in the deactivation of the Au catalyst (Figure 10) [78]. It was also observed that a minimum deactivation rate occurred at $100^{\circ} \mathrm{C}$. However, at this temperature, the activity of the Au catalyst was very low; it was not the optimum reaction temperature $[26,31,79]$. The deactivation of Au catalysts caused by a reduction of active components can be explained from the reaction mechanism of Au catalysts. Conte et al. reported that $\mathrm{AuCl}_{3}$ could absorb acetylene and $\mathrm{HCl}$, but the adsorption on acetylene was stronger. Acetylene has higher reducibility, which was one of the reasons for catalyst deactivation [5].

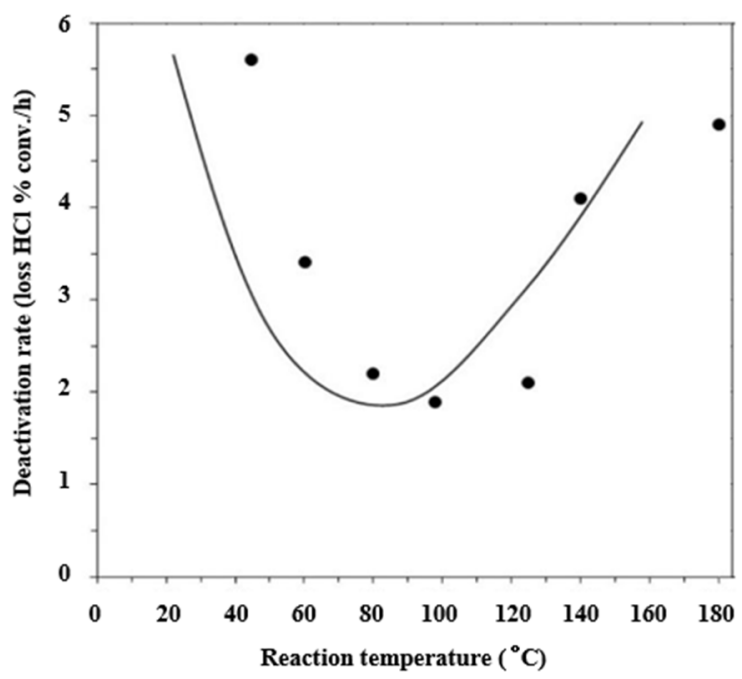

Figure 10. Effect of reaction temperature on rate of $\mathrm{Au}^{3+}$ catalyst deactivation [78].

For catalysts with $\mathrm{Au}^{3+}$ as the active center, the reduction of $\mathrm{Au}^{3+}$ is observed to be detrimental to catalyst activity [80]. One approach to improve the stability of $\mathrm{Au}^{3+}$ catalysts is to reactivate them. A large number of studies have shown that the deactivated Au catalyst can be regenerated by re-oxidation. Conte et al. demonstrated that a used catalyst can be regenerated by boiling aqua regia and a deactivation of $\mathrm{Au}$ catalyst was due to a loss of $\mathrm{Au}^{3+}$, which was restored by the aqua regia treatment [81]. $\mathrm{Cl}_{2}, \mathrm{NO}$, and $\mathrm{N}_{2} \mathrm{O}$ have been found to be effective in re-oxidation. These oxidants could alleviate the deactivation rate of catalyst [80]. Although $\mathrm{Au}^{3+}$ catalyst can be regenerated, the actual industrial application is still limited for various reasons.

The main reason for the deactivation of $\mathrm{Au}$ NPs with $\mathrm{Au}^{0}$ as the active species is the aggregation of Au NPs during acetylene hydrochlorination [82]. Malta et al. reported that single-site Au was the active site, but the formation of metallic $\mathrm{Au}$ particles by single-site $\mathrm{Au}^{0}$ was one reason for catalyst deactivation. Inelastic neutron scattering studies of $\mathrm{Au}^{0}$ catalysts exposed to acetylene showed that an oligomeric acetylene species formed on the catalyst surface. These oligomers could be precursors for carbon formation and become a deactivation process, thus significantly slowing down the reaction process (Figure 11) [83].

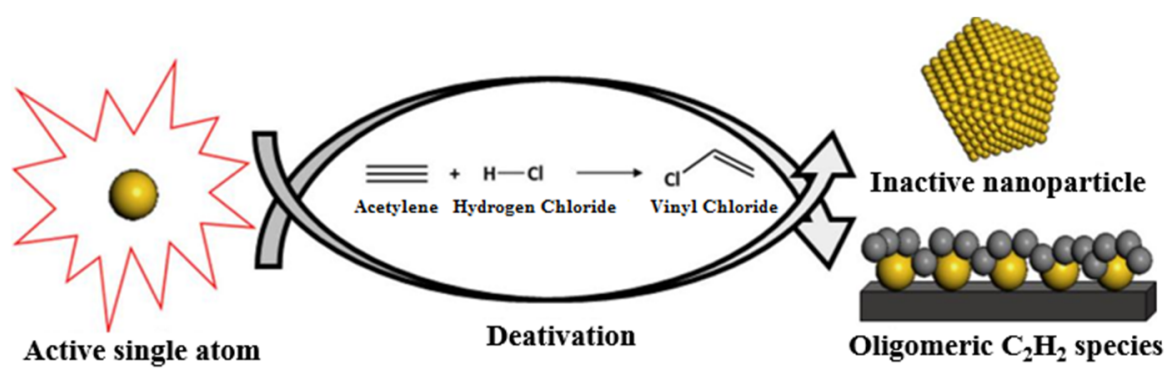

Figure 11. Deactivation of a single-site $\mathrm{Au}^{0}$ catalyst [83]. 


\section{2. $R u$ Catalysts}

The research on Ru catalysts has drawn considerable attention. In 2013, Zhu et al. calculated the activity parameters of $\mathrm{Au}, \mathrm{Hg}$, and $\mathrm{Ru}$ for acetylene hydrochlorination by DFT. The results showed that the calculated activation barrier was $16.3,11.9$, and $9.1 \mathrm{kcal} \mathrm{mol}^{-1}$ for $\mathrm{HgCl}_{2}$, $\mathrm{AuCl}_{3}$, and $\mathrm{RuCl}_{3}$, respectively. These results indicated that $\mathrm{RuCl}_{3}$ was a good candidate for the hydrochlorination of acetylene [84]. Table 3 summarizes and shows the performance of some Ru catalysts for acetylene hydrochlorination.

Table 3. Performance of Ru catalysts for acetylene hydrochlorination.

\begin{tabular}{|c|c|c|c|c|c|c|c|c|}
\hline Year & Catalyst & Material & Ru (wt \%) & $\begin{array}{c}\text { GHSV } \\
\left(h^{-1}\right)\end{array}$ & $\begin{array}{l}\text { Temp } \\
\left({ }^{\circ} \mathrm{C}\right)\end{array}$ & $\begin{array}{l}\text { Acetylene } \\
\text { Conv. (\%) }\end{array}$ & $\begin{array}{l}\text { Running } \\
\text { Time (h) }\end{array}$ & Ref. \\
\hline 2018 & $\mathrm{Ru}(\mathrm{III})-\mathrm{ChCl} / \mathrm{AC}$ & $\mathrm{RuCl}_{3}+\mathrm{ChCl}$ & 0.2 & 900 & 170 & 99.3 & 25 & [85] \\
\hline 2018 & $\mathrm{RuCl}_{3}-\mathrm{A} / \mathrm{AC}$ & $\mathrm{RuCl}_{3}+\mathrm{NH}_{3} \cdot \mathrm{H}_{2} \mathrm{O}$ & 2 & 100 & 180 & 95.8 & 8 & [87] \\
\hline 2016 & $\mathrm{Ru} / \mathrm{N}-\mathrm{AC}$ & $\mathrm{RuCl}_{3}$ & 1 & 57 & 250 & 95.2 & 180 & [90] \\
\hline 2013 & $\mathrm{Ru}_{1} \mathrm{Co}_{3} / \mathrm{SAC}$ & $\mathrm{RuCl}_{3}+\mathrm{CoCl}_{2}$ & 1 & 180 & 170 & 95 & 48 & [91] \\
\hline 2014 & $\mathrm{Ru} / \mathrm{SAC}-\mathrm{C} 300$ & $\mathrm{RuCl}_{3}$ & 1 & 180 & 170 & 96.5 & 48 & [92] \\
\hline 2016 & $\mathrm{Ru}-\mathrm{Co}(\mathrm{III})-\mathrm{Cu}(\mathrm{II}) / \mathrm{SAC}$ & $\begin{array}{c}\mathrm{RuCl}_{3}+\mathrm{CuCl}_{2}+ \\
\mathrm{Co}\left(\mathrm{NH}_{3}\right)_{6} \mathrm{Cl}_{3}\end{array}$ & 0.1 & 180 & 170 & 99 & 48 & [93] \\
\hline 2017 & $\mathrm{Ru} 10 \%[\mathrm{BMIM}] \mathrm{BF}_{4} / \mathrm{AC}$ & $\begin{array}{c}\mathrm{RuCl}_{3}+ \\
\text { 1-Butyl-3-methylimidazolium } \\
\text { tetrafluoroborate }\end{array}$ & 1 & 180 & 170 & 98.9 & 24 & [94] \\
\hline
\end{tabular}

Zhang et al. reported a series of Ru catalysts for acetylene hydrochlorination. Monometallic Ru, bimetallic $\mathrm{Ru}-\mathrm{Cu}$, and $\mathrm{Ru}-\mathrm{Co}$ were prepared on spheric active carbon (SAC) support. It was proposed that the addition of Co could enhance the catalytic activity and Ru species $\left(\mathrm{RuO}_{2}, \mathrm{Ru}^{0}, \mathrm{RuO}_{x}\right.$, and $\left.\mathrm{RuCl}_{3}\right)$ of the $\mathrm{Ru}$ catalyst [91]. It was found that the active ingredient of $\mathrm{RuO}_{2}$ was critical for improving the catalytic performance of Ru catalysts [92]. A series of trimetallic $\mathrm{Ru}-\mathrm{Co}^{3+}-\mathrm{Cu}^{2+} / \mathrm{SAC}$ catalysts were synthesized and evaluated for acetylene hydrochlorination. Compared with the monometallic and bimetallic catalysts, the trimetallic $\mathrm{Ru}-\mathrm{Co}^{3+}-\mathrm{Cu}^{2+} / \mathrm{SAC}$ catalyst with $0.1 \mathrm{wt} \% \mathrm{Ru}$ loading showed a superior catalytic performance with the acetylene conversion of $99.0 \%$. It was found that the addition of $\mathrm{Co}^{3+}$ and $\mathrm{Cu}^{2+}$ can help form highly dispersed $\mathrm{Ru}$ on the support, and $\mathrm{Cu}^{2+}$ species can not only inhibit the reduction of $\mathrm{RuCl}_{3}$ precursors but also facilitate the formation of $\mathrm{Co}^{3+}$ from $\mathrm{Co}^{2+}$ or $\mathrm{Co}^{0}$ (Figure 12) [93].

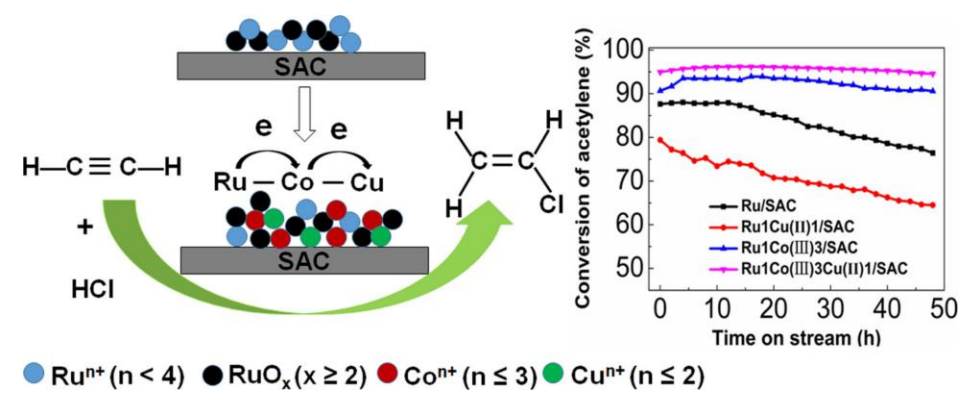

Figure 12. $\mathrm{Ru}-\mathrm{Co}^{3+}-\mathrm{Cu}^{2+} / \mathrm{SAC}$ catalyst for acetylene hydrochlorination [93].

In 2017, imidazolium-based ILs (IBILs) were reported. The optimal Ru10\% [BMIM] $\mathrm{BF}_{4} / \mathrm{C}$ catalyst achieved the acetylene conversion of $98.9 \%$ and the selectivity to VCM of $99.8 \%$. It was proposed that IBILs additives could improve the dispersion of Ru species and prevent coke deposition due to the

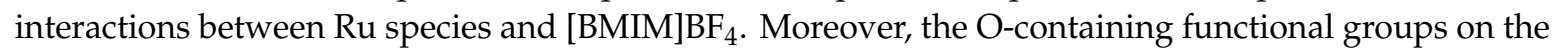
carbon support were involved in the interactions between Ru species and [BMIM] $\mathrm{BF}_{4}$ [94]. 


\subsection{Pt Catalysts}

There are a few reports on the catalytic hydrochlorination of acetylene by Pt catalysts, and the research mainly focuses on the catalytic mechanism. Mitchenko et al. conducted a series of studies on Pt catalysts. In their study, $\mathrm{K}_{2} \mathrm{PtCl}_{6}$ salt was treated under acetylene, ethylene, or propylene atmosphere to form a heterogeneous catalyst. It was shown that with this approach, the formation of $\mathrm{Pt}^{2+}$ complexes and $\mathrm{Pt}$ complexes with vacancies were observed. It was hypothesized that the active centers were defected in the form of impure $\mathrm{Pt}^{2+}$ ions in the $\mathrm{K}_{2} \mathrm{PtCl}_{6}$ matrix [95]. In 2004, Mitchenko et al. found that trans-d-VCM was formed in the DCl atmosphere. According to the established catalytic reaction mechanism on the active sites, a $\mathrm{K}_{2} \mathrm{PtCl}_{6}$ lattice that defected in the form of topologically bound coupled $\mathrm{PtCl}_{4}{ }^{2-}-\mathrm{PtCl}_{5}{ }^{-}$was formed by mechanical pre-activation under acetylene. Acetylene chloroplatination started first by coordination with an unsaturated $\mathrm{Pt}^{4+}$ complex producing an intermediate $\beta$-chlorovinyl $\mathrm{Pt}^{4+}$ derivative. The reduction of this intermediate yielded a $\mathrm{Pt}^{2+}$ organometallic derivative. The catalytic mechanism of acetylene hydrochlorination over the $\mathrm{Pt}$ catalyst is shown in Figure 13 [96].

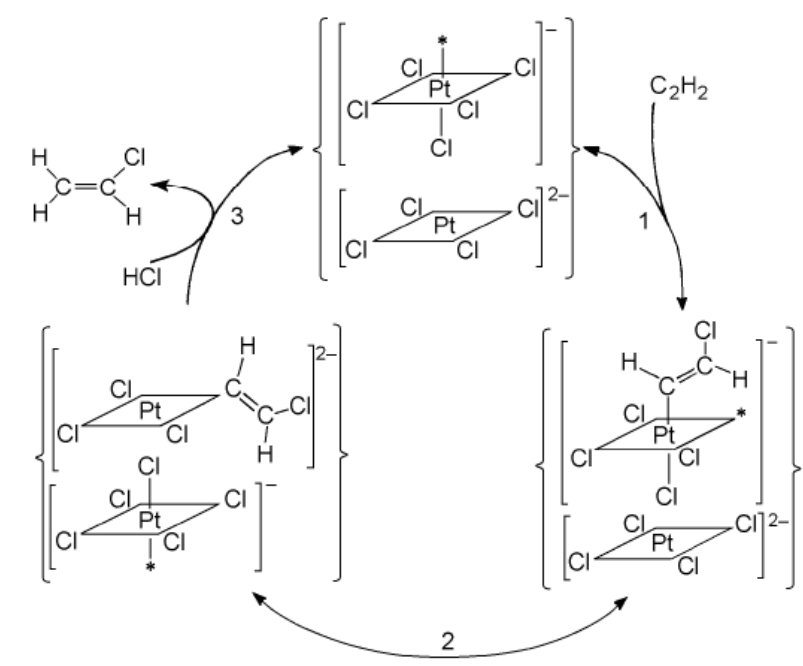

Figure 13. Catalysis mechanism of acetylene hydrochlorination over the Pt catalyst [96].

Mitchenko et al. also found that the catalytic reaction of acetylene chloroplatination proceeds in the form of $\pi$-acetylene complexes. The limiting step of the reaction was acetylene chloroplatination. It involved a $\pi$-acetylene complex and $\mathrm{HCl}$, producing a new $\pi$-acetylene $\mathrm{Pt}^{2+}$ complex and an intermediate $\beta$-chlorovinyl $\mathrm{Pt}^{2+}$ derivative. The protonolysis of the intermediates resulted in $\mathrm{VCM}$ formation [23]. In 2014, Mitchenko et al. reported that $\mathrm{HCl}$ was involved in two steps of acetylene hydrochlorination. With $\mathrm{K}_{2} \mathrm{MCl}_{4}(\mathrm{M}=\mathrm{Pt}$ or $\mathrm{Pd})$ and $\mathrm{K}_{2} \mathrm{PtCl}_{6}$ catalysts, the intermediate $\beta$-chlorovinyl derivative of $\mathrm{Pt}^{2+}$ was observed in protodemetallation over the Pt-containing catalysts [97].

\subsection{Pd Catalysts}

In 1985, Hutchings made Pd catalysts supported on carbon with relatively high initial activity for acetylene hydrochlorination but also found that $\mathrm{Pd}$ catalysts would be rapidly deactivated due to $\mathrm{Pd}^{2+}$ being reduced into $\mathrm{Pd}^{0}$ and carbon deposition [14]. Nkosi et al. reported that Pd catalysts were found to be as active as $\mathrm{Hg}$ catalysts on a mole basis. However, loadings of $\mathrm{PdCl}_{2}$ catalysts with durable stability were very low $(<1 \mathrm{wt} \%)$. At higher loadings, $\mathrm{PdCl}_{2}$ was rapidly lost from the catalyst presumably as a result of the formation of a volatile Pd acetylene complex. The loss of the average rate of conversion was $6.8 \%$ conv. $\mathrm{h}^{-1}$ during the first $3 \mathrm{~h}$ [16]. Strebelle et al. reported that $57.3 \%$ yield and a $96 \%$ selectivity for VCM was achieved with $\mathrm{PdCl}_{2}$ catalyst without a detailed description of catalyst stability [98]. 
Table 4 shows the performance of some Pd catalysts for acetylene hydrochlorination, in which the $\mathrm{Pd}^{2+}$ species is the active species.

Table 4. Performance of Pd catalysts for acetylene hydrochlorination.

\begin{tabular}{ccccccccc}
\hline Year & Catalyst & Material & Pd (wt \%) & $\begin{array}{c}\text { GHSV } \\
\left(\mathbf{h}^{-1}\right)\end{array}$ & $\begin{array}{c}\text { Temp } \\
\left({ }^{\circ} \mathbf{C}\right)\end{array}$ & $\begin{array}{c}\text { Acetylene } \\
\text { Conv. (\%) }\end{array}$ & $\begin{array}{c}\text { Running } \\
\text { Time }\end{array}$ & Ref. \\
\hline 2016 & $\mathrm{Pd} / \mathrm{PANI}-\mathrm{HY}$ & $\mathrm{H}_{2} \mathrm{PdCl}_{4}+$ polyaniline & 0.9 & 110 & 160 & 95 & $300 \mathrm{~h}$ & {$[99]$} \\
2016 & $\mathrm{Pd}-\mathrm{K} / \mathrm{NFY}$ & $\mathrm{PdCl}_{2}+\mathrm{KCl}+\mathrm{NH}_{4} \mathrm{~F}$ & 0.9 & 110 & 160 & 99 & $50 \mathrm{~h}$ & {$[100]$} \\
2015 & $\mathrm{Pd} / \mathrm{NH} 4 \mathrm{~F}-\mathrm{HY}$ & $\mathrm{PdCl}_{2}+\mathrm{NH}_{4} \mathrm{~F}$ & 0.9 & 110 & 160 & 99.92 & $400 \mathrm{~min}$ & {$[101]$} \\
2013 & $\mathrm{Pd} / \mathrm{HY}$ & $\mathrm{H}_{2} \mathrm{PdCl}_{4}$ & 0.5 & 110 & 160 & 95 & $160 \mathrm{~min}$ & {$[102]$} \\
2010 & $\mathrm{PdCl}_{2}-\mathrm{KCl}-\mathrm{LaCl} / \mathrm{C}$ & $\mathrm{PdCl}_{2}+\mathrm{KCl}+\mathrm{LaCl}_{3}$ & 0.9 & 120 & 160 & 99 & $3 \mathrm{~h}$ & {$[103]$} \\
\hline
\end{tabular}

Wang et al. reported that the presence of $\mathrm{NH}_{4} \mathrm{~F}$ in $\mathrm{Pd} / \mathrm{HY}$ catalysts can significantly improve the catalyst performance (acetylene conversion $>95 \%$ and VCM selectivity $>90 \%$ ). The hypothesis was that $\mathrm{NH}_{4} \mathrm{~F}$ could partially enhance the surface acidity, prevent carbon deposition, and slow down the loss of Pd (Figure 14) [101]. Wang et al. prepared a Pd catalyst (Pd/HY) with Y zeolite (HY) support. The catalyst exhibited excellent catalytic performance with $>95 \%$ acetylene conversion and $>90 \%$ VCM selectivity. The results showed that with the aid of ultrasonic-assisted impregnation, Pd was uniformly dispersed on the Y zeolite surface [102].

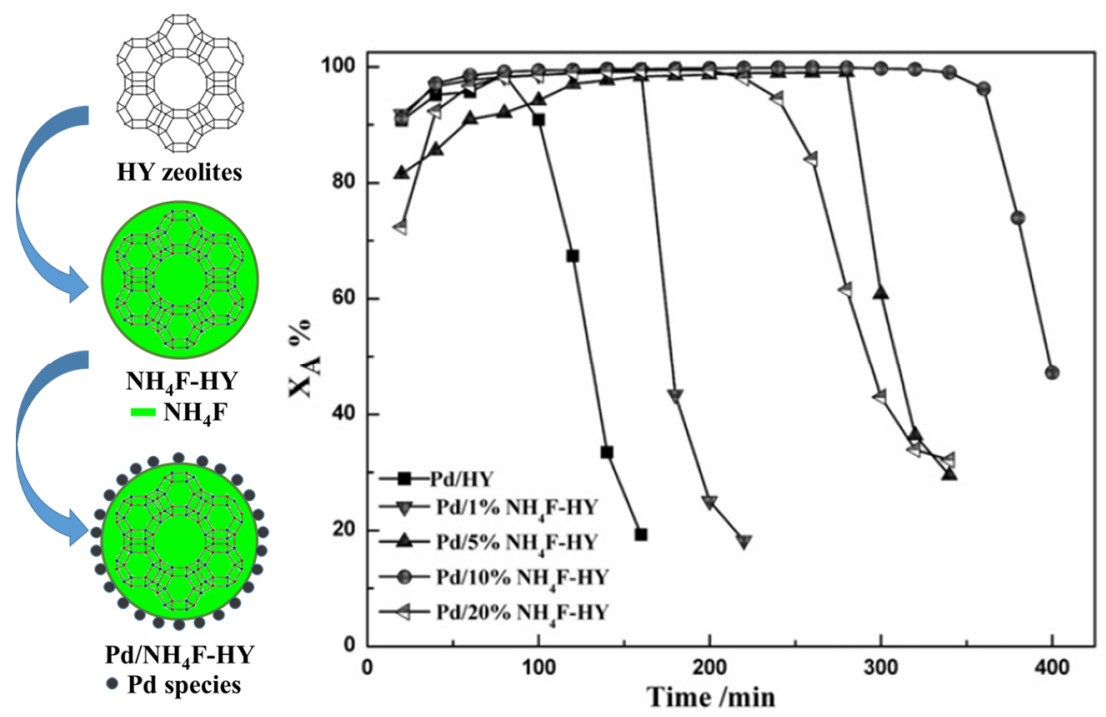

Figure 14. $\mathrm{Pd} / \mathrm{HY}$ catalysts modified with $\mathrm{NH}_{4} \mathrm{~F}$ for acetylene hydrochlorination. Adopted from Ref [101].

Song et al. reported that the deactivation of Pd catalysts were mainly from the loss of an active component, surface carbon deposition, and decrease in specific surface area. The results showed that the addition of $\mathrm{KCl}$ and $\mathrm{LaCl}_{3}$ can reduce the loss of $\mathrm{PdCl}_{2}$, increase the conversion of acetylene, and improve the selectivity of VCM. When the used $\mathrm{PdCl}_{2}-\mathrm{KCl}-\mathrm{LaCl}_{3} / \mathrm{C}$ catalyst was treated with $\mathrm{HNO}_{3}$ and $\mathrm{HCl}$, it can be re-activated to some extent by oxidation, but it is not as good as the original one [103].

$\mathrm{N}$-doped carbon materials and ILs were used to improve the catalytic performance of Pd catalysts. Li et al. demonstrated that $\mathrm{N}$ doping can prevent carbon deposition and improve the catalyst stability. The doped $\mathrm{N}$ atoms can act as a ligand, stabilizing $\mathrm{PdCl}_{2}$ and improving the surface activity [104]. Yang et al. reported IL-stabilized metal NPs (NPs@IL)-cosolvent liquid-liquid biphasic Pd NPs catalysts with improved performance for acetylene hydrochlorination. The NPs@IL droplets served as microreactors. The low viscosity organic phase enabled the rapid mass transfer. The acetylene conversion of $98 \%$ and VCM selectivity of $99.5 \%$ were achieved with this type of Pd catalyst [105]. Zhao et al. chose 1-butyl-3-methylimidazolium chloride ([Bmim] Cl) IL and activated carbon support 
to immobilize volatile catalytically active Pd complexes. The $0.5 \mathrm{Pd}-10 \mathrm{IL} / \mathrm{C}$ catalyst showed superior performance with $98.6 \%$ conversion of acetylene and above $99.8 \%$ selectivity to VCM. The influence of IL on the catalyst properties such as activity and stability was mainly due to the stabilization and dispersion of active Pd species in the IL layer, the possible coordination of the IL to the Pd atoms, and the confinement of Pd complexes within the pore's supports (Figure 15) [99].

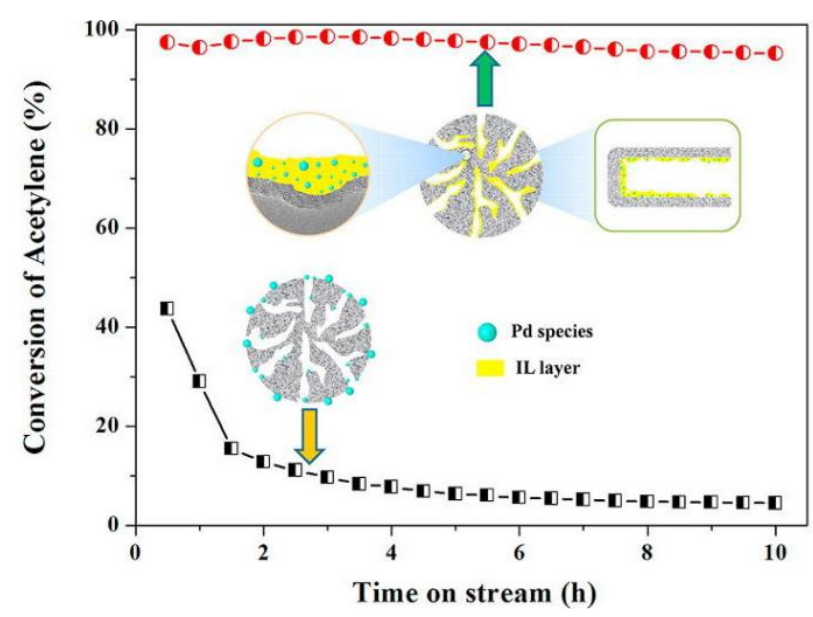

Figure 15. Supported IL-Pd catalyst for acetylene hydrochlorination [106].

\subsection{Challenge of Noble Metal Catalysts}

For the noble metal catalysts, the main problems of their industrialization are the high cost and short service life. There are mainly two problems that need to be solved: On the one hand, reducing the load of noble metals, which needs to be optimized from the catalyst formulation, and on the other hand, improving the stability of the noble metal catalyst. Therefore, the industrial application of noble metal catalysts should consider the reduction of noble metal catalyst loading capacity; at the same time, it should include a comprehensive consideration of support optimization, activated carbon pretreatment, additives, and catalyst preparation methods.

\section{Non-Noble Metal Catalysts}

Supported noble metal catalysts have the characteristics of high price and poor stability. Even the relatively good performance of Au catalyst is not able to meet the industrialization requirements for the economy and effect. Non-noble metal catalysts have become one of the catalysts with great potential for industrialization due to their advantages of being cheap and easy to obtain. At present, researches on non-noble metals are mainly focused on supported catalysts with $\mathrm{Cu}, \mathrm{Bi}$, and $\mathrm{Sn}$ as active centers.

\section{1. $\mathrm{Cu}$ Catalysts}

Compared with noble metals, $\mathrm{Cu}$ has the advantage of low price and easy availability with good thermal stability. Its price is relatively low, even in non-noble metals. In Hutchings' study, $\mathrm{Cu}^{2+}$ has a high potential of catalyzing acetylene hydrochlorination due to its high electrode potential. $\mathrm{Cu}$ is often used as an auxiliary agent in the modification of other metal active center catalysts [14]. In fact, acetylene hydrochlorination with $\mathrm{Cu}$ as the main active center has been reported as early as in 1933. US patent 1934324 first introduced $\mathrm{CuCl}$ catalyzed acetylene hydrochlorination as an active component [107]. Table 5 shows the performance of some $\mathrm{Cu}$ catalysts for acetylene hydrochlorination. 
Table 5. Performance of $\mathrm{Cu}$ catalysts for acetylene hydrochlorination.

\begin{tabular}{|c|c|c|c|c|c|c|c|c|}
\hline Year & Catalyst & Material & $\mathrm{Cu}(w \mathrm{t} \%)$ & $\begin{array}{l}\text { GHSV } \\
\left(h^{-1}\right)\end{array}$ & $\begin{array}{l}\text { Temp } \\
\left({ }^{\circ} \mathrm{C}\right)\end{array}$ & $\begin{array}{l}\text { Acetylene } \\
\text { Conv. (\%) }\end{array}$ & $\begin{array}{l}\text { Running } \\
\text { Time }\end{array}$ & Ref. \\
\hline 2018 & $\mathrm{Cu}-\mathrm{Cs} / \mathrm{AC}$ & $\mathrm{CuCl}_{2}+\mathrm{CsCl}$ & 1 & 50 & 200 & 92 & 200 & [108] \\
\hline 2016 & $\mathrm{Cu}-\mathrm{g}-\mathrm{C}_{3} \mathrm{~N}_{4} / \mathrm{AC}$ & $\mathrm{CuCl}_{2}+$ dicyan-diamide & 4.15 & 72 & 180 & 79 & $450 \mathrm{~min}$ & [109] \\
\hline 2015 & $\mathrm{Cu}_{2} \mathrm{P}_{2} \mathrm{O}_{7} / \mathrm{SAC}$ & $\mathrm{Cu}_{2} \mathrm{P}_{2} \mathrm{O}_{7}$ & 15 & 180 & 140 & 40.5 & $500 \mathrm{~min}$ & [110] \\
\hline 2015 & $\mathrm{Cu} 400 \mathrm{Ru} / \mathrm{MWCNTs}$ & $\mathrm{CuCl}_{2}+\mathrm{RuCl}_{3}$ & 4.24 & 180 & 180 & 51.6 & $6 \mathrm{~h}$ & [111] \\
\hline 2014 & Cu-NCNT & $\begin{array}{l}\mathrm{CuCl}_{2}+\mathrm{N} \text {-doped } \\
\text { carbon nanotubes }\end{array}$ & 5 & 180 & 180 & 45.8 & $4 \mathrm{~h}$ & [112] \\
\hline
\end{tabular}

Zhao et al. found that $\mathrm{Cu}-\mathrm{g}-\mathrm{C}_{3} \mathrm{~N}_{4} / \mathrm{AC}$ significantly improved catalytic performance compared to the catalyst without $\mathrm{N}$ doping. The authors hypothesized that after doping, pyrrolic $\mathrm{N}$ promoted the adsorption of $\mathrm{HCl}$ and acetylene, and it inhibited the coke deposition on the catalyst surface [109]. $\mathrm{Li}$ et al. reported that the P-doped $\mathrm{Cu}$ demonstrated good stability and catalytic activity. The amount of $\mathrm{P}$ used was critical and significantly influenced the catalyst activity. It was assumed that $\mathrm{P}$ doping enhanced the interaction between metal and support, improved the dispersity of $\mathrm{Cu}$, retarded the reduction of the active components $\left(\mathrm{Cu}^{2+} / \mathrm{Cu}^{+}\right)$to $\mathrm{Cu}^{0}$, and effectively prevented the aggregation of $\mathrm{Cu}$ particles [110]. Zhou et al. reported that N-doped carbon nanotubes (N-CNTs) improved the electron conductivity ability of the carbon sheets as well as the interaction between $\mathrm{Cu}$ and N-CNTs, and the improvement of the adsorption capacity of acetylene led to high catalytic activity and excellent VCM selectivity. The active components were proposed to be a mixture of $\mathrm{Cu}^{+}$and $\mathrm{Cu}^{2+}$. It was speculated that acetylene hydrochlorination preferred to take place at binding sites of $\mathrm{Cu}$ and $\mathrm{N}$ (Figure 16) [112].

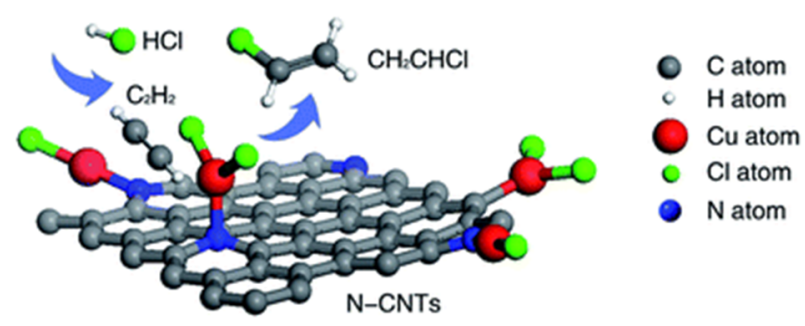

Figure 16. Cu-N-CNT catalyst for acetylene hydrochlorination [112]. N-CNT: N-doped carbon nanotubes.

In the preparation of $\mathrm{Cu}$ catalysts, the addition of promoters such as metal chlorides and rare earth oxides can improve the catalytic performance. Shi et al. reported that the catalyst $\mathrm{La}_{1.7} \mathrm{~K}_{0.3} \mathrm{NiMnO}_{6}-\mathrm{CuCl}_{2} / \gamma-\mathrm{Al}_{2} \mathrm{O}_{3}$ doped with $\mathrm{K}$ had a large amount of $\mathrm{Mn}^{4+}$ and surface-adsorbed oxygen. These species accelerated the oxidation of $\mathrm{Cu}^{+}$and released $\mathrm{Cl}_{2}$ [3]. $\mathrm{Xu}$ et al. reported a catalyst consisting of $400 \mathrm{ppm} \mathrm{Ru}$ and $4.24 \mathrm{wt} \% \mathrm{Cu}$. Carbon nanotubes were chosen as the support. The synergistic effect between $\mathrm{Ru}$ and $\mathrm{Cu}$ led to a high activity $\left(\mathrm{TOF}=1.81 \mathrm{~min}^{-1}\right)$ [111]. Zhai et al. synthesized a perovskite-like catalyst for acetylene hydrochlorination. The $\mathrm{CsCuCl}_{3} \mathrm{NPs}$ were supported on activated carbon with $1 \mathrm{wt} \% \mathrm{Cu}$ content, which exhibited superior performance compared with a pure $\mathrm{Cu}$ catalyst without $\mathrm{Cs}$. The formation of the perovskite-like $\mathrm{CsCuCl}_{3} \mathrm{Complex}$ structure stabilized the active $\mathrm{Cu}^{2+}[108]$.

In order to improve the performance of $\mathrm{Cu}$ catalysts, efforts were attempted by modifying the support and adding promoters for improving the dispersion of $\mathrm{Cu}$. The modification did not change the structure of the $\mathrm{Cu}$ active center. The preparation of a highly dispersed $\mathrm{Cu}$ catalyst is complex and is limited for large-scale industrial production. The addition of expensive noble metals can increase the catalytic activity of $\mathrm{Cu}$ catalysts; however, the advantage of cheap and easy availability of non-noble metal catalysts has been lost. 


\subsection{Other Non-Noble Metal Catalysts}

Zhou et al. synthesized a $\mathrm{Bi} / \mathrm{Cu} / \mathrm{H}_{3} \mathrm{PO}_{4}$ catalyst supported by silica gel. The catalyst exhibited acceptable initial activity ( $30 \%$ activity of $\mathrm{Hg}$ catalyst) and stability at $200{ }^{\circ} \mathrm{C}$ and GHSV $360 \mathrm{~h}^{-1}$. The catalyst could be recovered by a two-step regeneration method [11]. Hu et al. found that the doping of $S$ increased the Brunauer-Emmett-Teller (BET) surface areas and decreased the active species particle size of the Bi catalyst, which led to more accessible active sites and consequently boosted the catalytic activity in hydrochlorination. The main active components of the catalyst is $\mathrm{BiOCl}$ crystal particle, and the coke deposition was responsible for the deactivation of the Bi catalyst [113].

Dai et al. developed a series of transitional metal catalysts. In their work, Mo and Ti were chosen as the active ingredients in a catalyst for acetylene hydrochlorination. With this catalyst, $89 \%$ acetylene conversion and $>98.5 \%$ VCM selectivity can be obtained. The doping of Mo and Ti reduced the adsorption capacity for acetylene while increasing the adsorption of $\mathrm{HCl}$ [114]. The authors reported three transition metal nitride $\mathrm{VN} / \mathrm{C}, \mathrm{Mo}_{2} \mathrm{~N} / \mathrm{C}$, and $\mathrm{W}_{2} \mathrm{~N} / \mathrm{C}$ catalysts on activated carbon. With these catalysts, $98 \%$ VCM selectivity was achieved [115]. For $\mathrm{W}_{2} \mathrm{~N}$, two catalysts were prepared. The first was prepared by depositing $\mathrm{W}$ onto activated carbon, whereas the second was prepared in the same procedure except for extra plasma treatment. The author claimed that plasma treatment increased the interaction between active ingredients and support material. The results showed that plasma treatment increased the number of $\mathrm{W}-\mathrm{N}$ bonds and restricted the deposition of coke, thus enhancing the catalytic performance [116]. They found that the Co-N-AC catalyst effectively improved the adsorption of $\mathrm{HCl}$. The presence of $\mathrm{Co}-\mathrm{N}_{x}$ played a major role in acetylene hydrochlorination (Figure 17) [117].

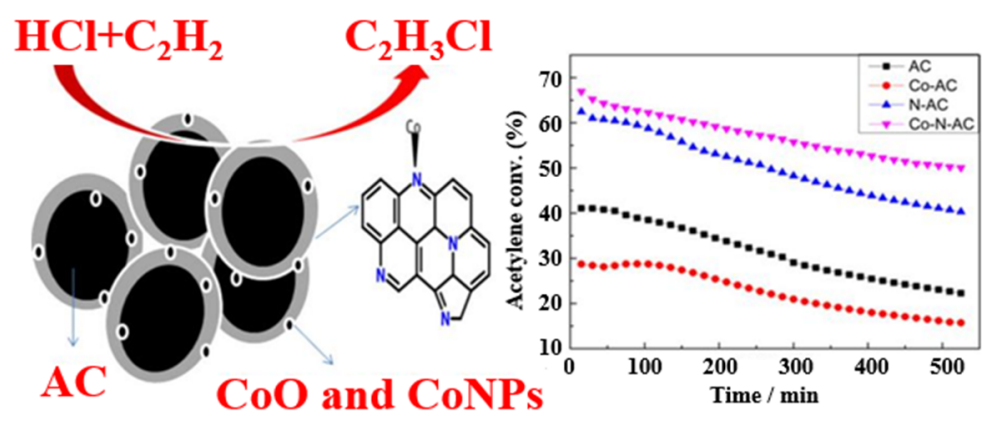

Figure 17. Co-N-AC catalyst for acetylene hydrochlorination [117].

\subsection{Challenge of Non-Noble Metal Catalysts}

At present, the research of non-noble metals catalysts is largely confined to the laboratory stage. Non-noble metal catalysts are constantly modified and improved to increase their activity and stability by adding additives or using bimetallic or trimetallic catalysts. However, there are still challenges and limitations, such as low monomer conversion rate, poor selectivity of $\mathrm{VCM}$, severe carbon accumulation, loss of catalytic activity over time, unsatisfactory stability, and short lifetime.

\section{Non-Metallic Catalysts}

An alternative approach to replace $\mathrm{Hg}$ catalysts is to develop the non-metallic catalysts. Non-metallic catalysts are newly emerging green catalytic materials that have attracted much attention in recent years due to their advantages of environmental friendliness and low cost.

\subsection{Carbon Material Catalysts}

The research of carbon catalysts is mainly about the structural defect sites, the regulation of functional groups on the carbon materials surface, and the doping of heteroatoms. Non-metallic nanocarbon materials for acetylene hydrochlorination have been intensively investigated by many researchers (Table 6). 
Table 6. Performance of carbon material catalysts for acetylene hydrochlorination.

\begin{tabular}{|c|c|c|c|c|c|c|c|}
\hline Year & Catalyst & Material & $\begin{array}{l}\text { GHSV } \\
\left(h^{-1}\right)\end{array}$ & $\begin{array}{l}\text { Temp } \\
\left({ }^{\circ} \mathrm{C}\right)\end{array}$ & $\begin{array}{l}\text { Acetylene } \\
\text { Conv. (\%) }\end{array}$ & $\begin{array}{l}\text { Running } \\
\text { Time (h) }\end{array}$ & Ref. \\
\hline 2019 & ND@G & Nanodiamond + graphene & 300 & 220 & 50 & 10 & [118] \\
\hline 2018 & ZIF-8/SAC & $\begin{array}{l}\text { ZIF-8 + spherical } \\
\text { activated carbon }\end{array}$ & 30 & 220 & 81 & 2 & [119] \\
\hline 2018 & NS-C-NH 3 & $\mathrm{~S}+\mathrm{N}$-doped carbon $+\mathrm{NH}_{3}$ & 35 & 220 & 80 & 9 & [120] \\
\hline 2017 & $\mathrm{p}-\mathrm{BN}$ & $\mathrm{H}_{3} \mathrm{BO}_{3}+$ melamine $+\mathrm{NH}_{3}$ & - & 280 & 99 & 50 & [121] \\
\hline 2016 & Z4M1 & ZIF-8 + melamine & 50 & 180 & 60 & 20 & [122] \\
\hline 2015 & $\mathrm{~B}, \mathrm{~N}-\mathrm{G}$ & $\begin{array}{c}\text { Graphene oxide }+ \\
\mathrm{H}_{3} \mathrm{BO}_{3}+\mathrm{NH}_{3}\end{array}$ & 360 & 150 & 94.87 & 4 & [123] \\
\hline 2014 & N-OMC-700 & $\begin{array}{l}\text { N-doped ordered } \\
\text { mesoporous carbon }\end{array}$ & - & 200 & 77 & 100 & [124] \\
\hline 2014 & $\mathrm{~N}-\mathrm{CNTs}$ & $\mathrm{C}_{2} \mathrm{H}_{4}+\mathrm{NH}_{3}$ & 180 & 180 & 7.2 & 3 & [125] \\
\hline 2014 & $\mathrm{~g}-\mathrm{C}_{3} \mathrm{~N}_{4}$ & $\begin{array}{l}\text { Activated carbon }+ \\
\text { cyanamide }\end{array}$ & 50 & 180 & 76.52 & 7 & [69] \\
\hline 2014 & PSAC-N & $\begin{array}{c}\text { Pitch-based spherical } \\
\text { activated carbon }+ \text { melamine }\end{array}$ & 120 & 250 & 68 & - & [126] \\
\hline
\end{tabular}

Efforts have been devoted to improving the activity and stability of catalysts by modifying carbon-based catalysts. The most common materials studied are $\mathrm{N}$-doped carbon materials. $\mathrm{N}$-containing carbon materials are often prepared by heating different $\mathrm{N}$-containing precursors under $\mathrm{N}_{2}$ atmospheres or direct carbonization [7,70]. It was hypothesized that the incorporation of $\mathrm{N}$ atoms could tune the basicity of carbon materials surface. The $\mathrm{N}$ atoms could also provide available lone pairs, which can facilitate a hydrochlorination reaction.

$\mathrm{Li}$ et al. prepared a series of zeolitic imidazolate framework (ZIF)-derived N-doped carbon using melamine as $\mathrm{N}$ sources. Additions of melamine not only facilitated forming a special morphological structure and pore structure but also adjusted the relative content ratio of three $\mathrm{N}$ species in ZIF-derived N-doped carbon materials [122]. Li et al. reported that N-doped ordered mesoporous carbon (N-OMC) with high surface areas processed high activity and stability. A 77\% acetylene conversion and $98 \%$ VCM selectivity was obtained over the $100 \mathrm{~h}$ test period. The N-OMC activity increased with the increasing of the catalyst surface area and $\mathrm{N}$ content [124]. Wang et al. prepared an N-doped pitch-based spherical activated carbon catalyst (PSAC-N) with melamine. The active site of PSAC-N had a special N-6v structure in which quaternary $\mathrm{N}$ bonded between two 6-membered rings. Compared to controls, the adsorption capacity of $\mathrm{HCl}$ on PSAC-N was the highest, which was beneficial for acetylene hydrochlorination. The reaction energy of N-6v(7) was calculated as $236.2 \mathrm{~kJ} \mathrm{~mol}^{-1}$ [126]. Li et al. reported that the $\mathrm{g}-\mathrm{C}_{3} \mathrm{~N}_{4} / \mathrm{C}$ catalyst prepared with cyanamide as a precursor displayed considerable catalytic performance. $\mathrm{C}_{3} \mathrm{~N}_{4}$ was able to adsorb and activate acetylene and $\mathrm{HCl}$ simultaneously, and the strong $\mathrm{C}(1)-\mathrm{C}(2)$ interaction led to the formation of a stable $\mathrm{CHCl}=\mathrm{CH}-\mathrm{C}_{3} \mathrm{~N}_{4} \mathrm{H}$ unit that provided a rate-controlling step $\left(\mathrm{E}_{\text {act }}=77.94 \mathrm{kcal} \mathrm{mol}^{-1}\right.$ [69]). Qian et al. synthesized a g- $\mathrm{C}_{3} \mathrm{~N}_{4}$ framework with rich $\mathrm{N}$ defects using melamine formaldehyde as a precursor. The fragmentary g- $\mathrm{C}_{3} \mathrm{~N}_{4}$ showed high catalytic activity with $94.5 \%$ acetylene conversion, which was 30 times higher than that of pure g- $\mathrm{C}_{3} \mathrm{~N}_{4}$. The improvements were attributed to the etching of the g- $\mathrm{C}_{3} \mathrm{~N}_{4}$ framework by $\mathrm{O}$ species in the melamine formaldehyde resin. Moreover, DFT calculations showed that the $\mathrm{N}$ defects in the g- $\mathrm{C}_{3} \mathrm{~N}_{4}$ framework greatly improved the adsorption of $\mathrm{HCl}$ and acetylene and brought down the energy barrier from 62.0 to $38.1 \mathrm{kcal} \mathrm{mol}^{-1}$ [127]. Zhang et al. reported that the $\mathrm{N}$-doped carbon catalyst with polyaniline had significantly improved catalytic activity and stability (Figure 18). The catalytic performance of this catalyst was closely related to pyrrolic $\mathrm{N}$ (pyrrolic $\mathrm{N}>$ graphitic $\mathrm{N}>$ pyridinic $\mathrm{N}$ ) [128]. 


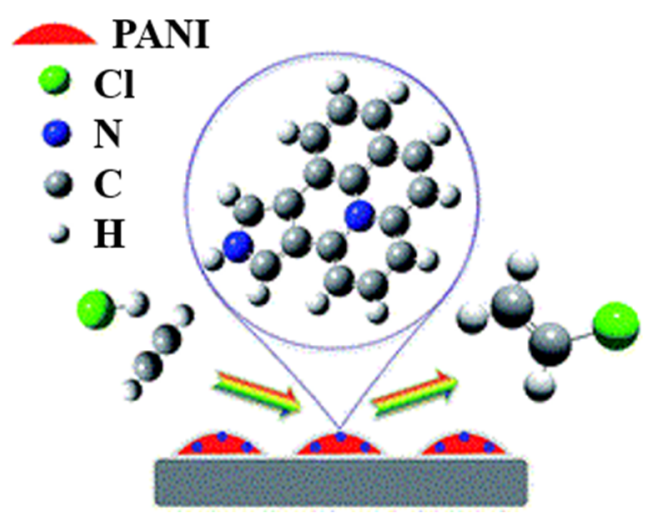

Figure 18. N-doped active carbon catalyst for acetylene hydrochlorination [128].

Lan et al., reported nanodiamond-raphene composed of a nanodiamond core and graphitic shell with defects. The catalyst showed pretty high catalytic activity, which was comparable with metal catalysts for acetylene hydrochlorination. Figure 19 shows that the defects on the carbon surface and edge were assumed to be desirable for acetylene hydrochlorination [118]. Zhou et al. found that N-CNTs featured good catalytic activity (TOF $\left.=2.3 \times 10^{-3} \mathrm{~s}^{-1}\right)$ and high VCM selectivity $(>98 \%)$. There was an observable correlation between the quaternary $\mathrm{N}$ content and acetylene conversion. DFT calculation revealed that $\mathrm{N}$ doping enhanced the interaction between acetylene and $\mathrm{N}-\mathrm{CNTs}$ compared with the CNTs without N [125]. Cyanamide and its derivatives are common raw materials for preparing $\mathrm{N}$-doped carbon catalysts. Li et al. reported ZIF-8-derived NPs featuring more active sites, which were easily accessible for reactants $\mathrm{HCl}$ and acetylene. Bamboo-shaped CNTs promoted the efficiency of active site $\mathrm{N}$, changed the porosity of the catalyst, and inhibited the formation of coke deposition [119]. Zhao et al. proposed that the defects in graphene could be useful to improve the catalytic performance for acetylene hydrochlorination based on the DFT calculated [129].

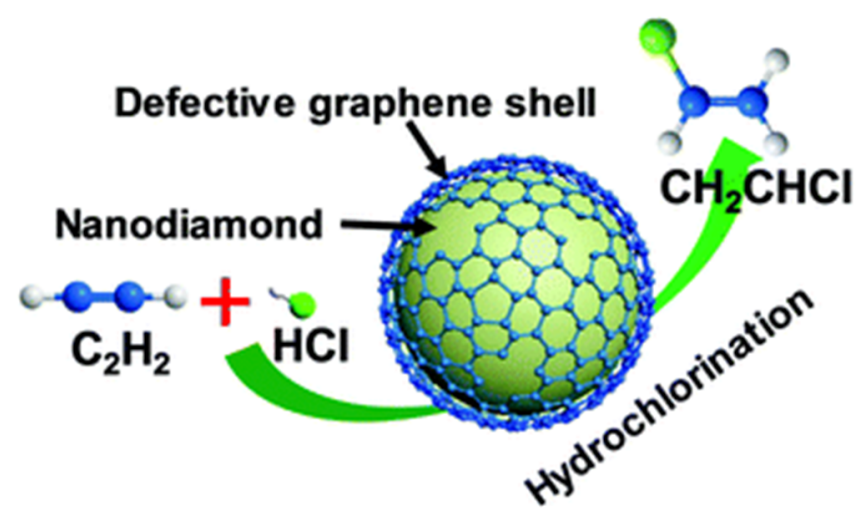

Figure 19. Defective nanodiamond-graphene catalyst for acetylene hydrochlorination [118].

Dual heteroatom doping was also attempted for catalyst design. Dong et al. reported that an $\mathrm{S}$ and $\mathrm{N}$ co-doped carbon catalyst exhibited a higher acetylene conversion than the $\mathrm{N}$-doped carbon. The $\mathrm{C}$ atoms adjacent to pyridinic $\mathrm{N}$ were found to be active sites, and $\mathrm{S}$ improved the pyridinic $\mathrm{N}$ content in N-doped carbon materials (Figure 20) [120]. Li et al. reported that porous boron nitride (p-BN) was active for acetylene hydrochlorination. The activity of $\mathrm{p}-\mathrm{BN}$ was originated from the defects and edge sites. Particularly, the armchair edges of $\mathrm{p}-\mathrm{BN}$ can polarize and activate acetylene, which react with $\mathrm{HCl}$ to form VCM [121]. Dai et al. synthesized B and $\mathrm{N}$ heteroatoms dual doped on a graphene oxide $(\mathrm{B}, \mathrm{N}-\mathrm{G})$ catalyst. With this catalyst, acetylene conversion is near $95 \%$, which is significantly higher than that of singly B- or N-doped graphene. The authors proposed that the synergistic effect of $\mathrm{B}$ and $\mathrm{N}$ doping promoted $\mathrm{HCl}$ adsorption (Figure 21) [123]. Li et al. reported an 
$\mathrm{N}$-doped carbon nanocomposite derived from silicon carbide. It was found that the catalyst activated acetylene directly in which $\mathrm{C}$ atoms bonded with pyrrolic $\mathrm{N}$ were the active sites [130]. Zhao et al. found that the doping of $\mathrm{C}$ atoms on boron nitride (BN) cages can significantly promote the adsorption ability of the acetylene molecule compared with the BN cages without doping. Acetylene was adsorbed onto $\mathrm{B}_{12-n} \mathrm{~N}_{11+n} \mathrm{C}(n=0,1)$ clusters prior to $\mathrm{HCl}$ and then formed three adsorption states: two trans configuration and one cis configuration. The energy barrier of the minimum energy pathway based on $\mathrm{B}_{11} \mathrm{~N}_{12} \mathrm{C}$ catalyst was as low as $36.08 \mathrm{kcal} \mathrm{mol}^{-1}$ [131].

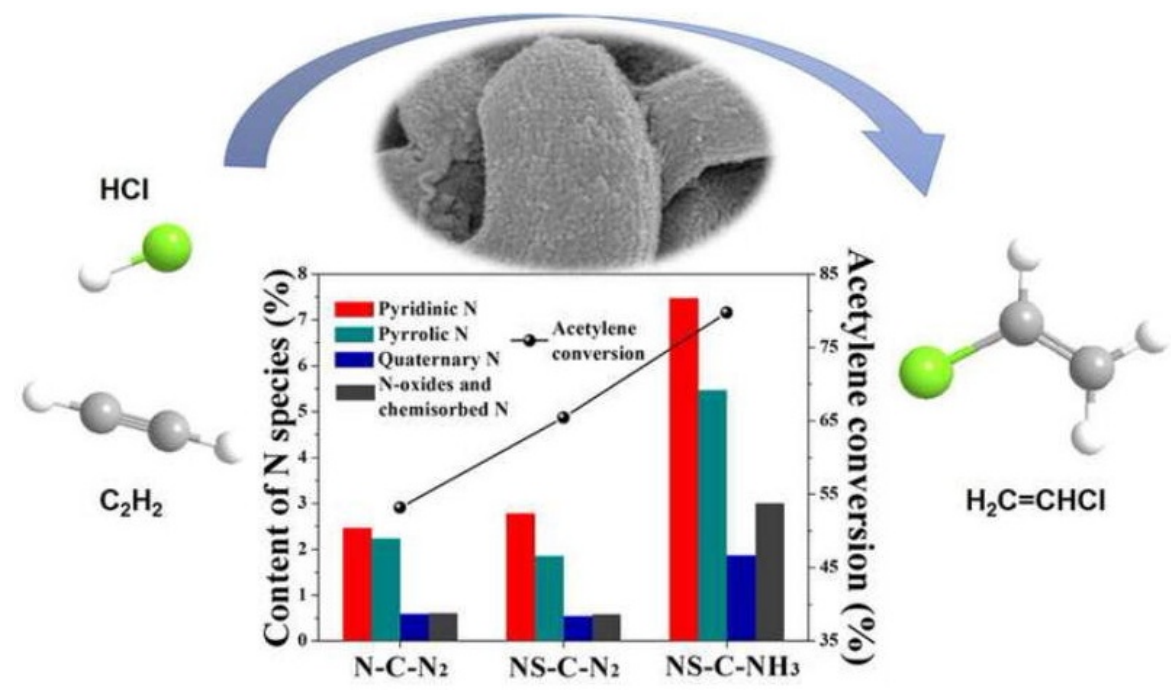

Figure 20. S and N co-doped carbon catalyst for acetylene hydrochlorination [120].

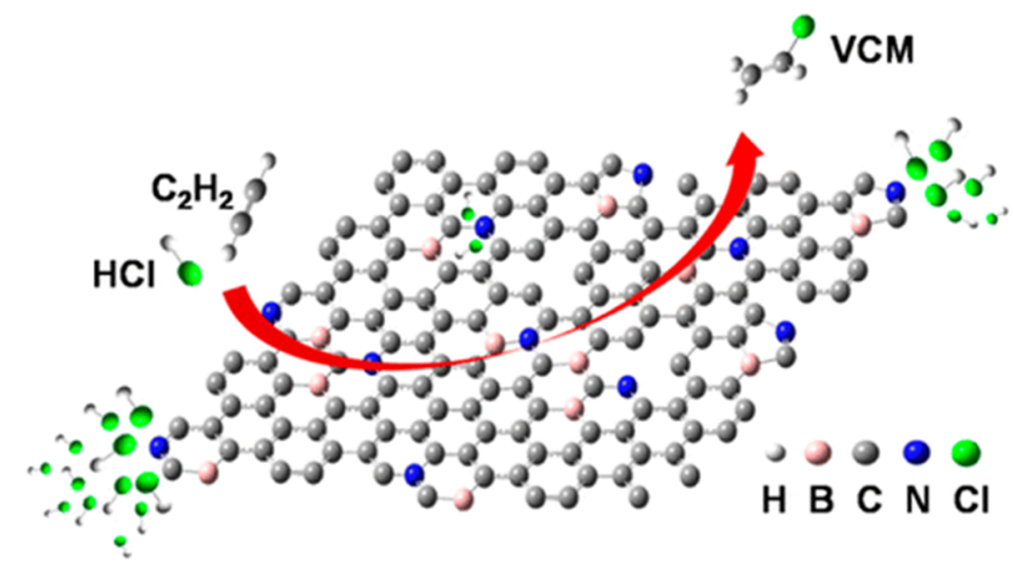

Figure 21. B,N-graphene catalyst for acetylene hydrochlorination [123].

The deactivation mechanism of $\mathrm{N}$-doped carbon catalysts has been studied. Li et al. reported that a PDA/SiC composite with high activity and stability can be prepared by coating silicon carbide with polydopamine (PDA). The catalyst deactivation was caused presumably by the carbon deposition, which can be regenerated with $\mathrm{NH}_{3}$ treatment at high temperature [132]. Chao et al. reported that $\mathrm{C}$ atoms adjacent to the pyridinic $\mathrm{N}$ were the active sites of $\mathrm{N}$-doped carbon catalyst derived from ZIF-8. Coke deposition over pyridinic $\mathrm{N}$ was responsible for catalyst deactivation [133].

\subsection{Other Non-Metallic Catalysts}

Zeolites not only have a large specific surface area and unique pore structure, but also have abundant active sites and acid centers. Therefore, zeolites are widely adopted as catalysts in the chemical industry. Song et al. investigated the activity of faujasite (FAU) zeolite 13X for 
acetylene hydrochlorination without loading any metal. It was found that the FAU zeolite $13 \mathrm{X}$ demonstrated observable activity presumably from its abundant micropores and unique supercage; acetylene conversion was up to $98.5 \%$. Na cations in the zeolite framework could facilitate acetylene hydrochlorination. The deactivation of $13 \mathrm{X}$ was probably due to the collapse of its crystal structure and severe carbon deposit. The spent catalyst could be partly regenerated by calcination [134].

ILs are well-known green solvents. They have unique physicochemical properties involving high solubility, high thermal stability, and negligible volatility, and they have been applied in many fields including catalysis, adsorption, and organic synthesis. Li et al. found that tetraphenylphosphonium bromide (TPPB) ILs exhibited strong adsorption for $\mathrm{HCl}$ but weak adsorption for acetylene. At the catalytic active site of TPPB, the activation energy of acetylene hydrochlorination was $21.15 \mathrm{kcal} \mathrm{mol}^{-1}$, which is much lower than that without a catalyst $\left(44.29 \mathrm{kcal} \mathrm{mol}^{-1}\right)$. During the reaction, the $\mathrm{H}-\mathrm{Cl}$ bond was preferentially activated through the electrons transfer from the anion of TPPB; then, acetylene was activated to undergo the addition of $\mathrm{H}$ and $\mathrm{Cl}$. Such unique preferential activation toward the $\mathrm{H}-\mathrm{Cl}$ bond significantly promoted the catalytic activity and the stability of TPPB catalysts. The catalyst has good catalytic activity and stability, and the highest acetylene conversion rate was $97.1 \%$ [135]. Wang et al. investigated the catalytic performance of imidazolium-based ILs 1-ethyl-3-methylimidazolium tetrafluoroborate ([Emim][BF 4$]$ ) (IL/CaX) for acetylene hydrochlorination with a nearly $90 \%$ acetylene conversion. The reaction proceeded via a two-site mechanism. $\mathrm{HCl}$ adsorbed on the $\mathrm{Ca}^{2+}$ in zeolite reacted with acetylene adsorbed on IL cations to form VCM. The catalytic reaction occurred at the IL/CaX interface, while the IL/CaX in the upper interphase had no activity. Catalyst deactivation was mostly caused by by-products dissolved in the IL and can be reactivated by a simple vacuum process [136]. Moreover, Zhou et al. reported that 1-alkyl-3-methyimidazolium-based ILs as metal-free catalysts have to consist of the chloride anion due to its participation in acetylene hydrochlorination with the formation of $\left[\mathrm{HCl}_{2}\right]^{-}$by the activation of $\mathrm{HCl}$ molecules. The structural modification of conjugated cation in ILs was the key to promote the catalytic activity (Figure 22) [137].

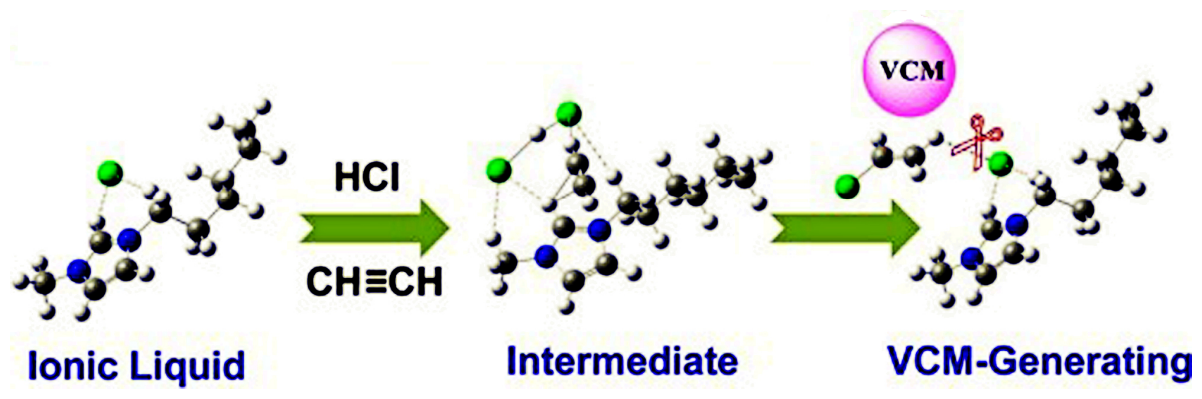

Figure 22. ILs catalyst for acetylene hydrochlorination [137].

\subsection{Challenge of Non-Metallic Catalysts}

The design and development of non-metallic catalysts for acetylene hydrochlorination has been widely studied in recent years. It is worth looking forward to the application of non-metallic catalysts in industry as an economical and environmentally friendly approach. However, most of the non-metallic catalytic materials reported at present have some intrinsic disadvantages, which limit the practical industrial applications. Researchers are working vigorously to meet the needs and requirements of viable catalysts in the production of the VCM industry. Although non-metallic doped catalysts, especially $\mathrm{N}$-doped carbon catalysts, have been used in many reactions, there are still some problems and hurdles for acetylene hydrochlorination. The first is that the reaction mechanism of different $\mathrm{N}$ species (pyridine $\mathrm{N}$, pyrrole $\mathrm{N}$, and graphite $\mathrm{N}$ ) has not yet been determined. In addition, the highest conversion rate of acetylene for $\mathrm{N}$-doped carbon catalysts is about $95 \%$, which reasonably matches the industrial space velocity. Compared with the acetylene conversion rate of $\mathrm{Hg}$ or even Au catalyst 
approaching $100 \%$ at extreme space velocity, a significant amount of work needs to be done to improve both acetylene conversion and VCM selectivity.

Compared with solid-phase catalysts, ILs have some advantages in activity and stability. However, it is difficult to separate the reaction products from the catalysts, and there are also issues in the recovery and reuse of deactivated catalysts.

\section{Future Prospects}

Acetylene hydrochlorination is an important reaction in the traditional coal (chlor-alkali) chemical industry. The main problems of mercury-free catalyst with noble metals are the high application cost and short catalyst life.

High cost has become the biggest issue to the industrial application of noble metal catalysts. Reducing the content of noble metal alongside improving the stability and life of the catalysts are very critical in the research and development of noble metal catalysts. The following aspects of research need to be strengthened as well. The first is to develop or find better support materials. The commonly used activated carbon has well-developed pores. The distribution of pores is very extensive, and the existence of functional groups is very rich. At present, research on the microstructure and internal properties of activated carbon are relatively few. It is necessary and meaningful to continue to develop high-performance carbon supports that are suitable for acetylene hydrochlorination with a large specific surface area, appropriate pore size, and suitable internal chemical properties. At the same time, it is important to find ways to improve the reaction efficiency of noble metal catalysts by actively developing new supports other than carbon materials. The second is to look for non-noble metal additives that could be substituents of noble metal active components. By adding non-noble metal active components or additives, one would expect to see coordination and collective effects in improving catalyst performance. Meanwhile, the use of noble metals can also be reduced to lower the cost of the catalyst. The third is to find a better way to support the noble metal components so as to have dispersity at the nanometer level while maintaining durable stability and robustness. It is easy for the traditional simple impregnation method to cause the aggregation and agglomeration of the active components, which quickly bring down the catalytic activity of noble metal species and limit their applications. A reasonable loading mode can provide more active centers for noble metal components per unit mass, so as to improve the catalytic efficiency of noble metal particles and reduce noble metal content. Finally, the regeneration and recycling of noble metal catalysts are also very important. If the noble metal can be reused well, the problem of high price and high cost of catalyst may be solved.

The problems of non-noble metal and non-metallic catalysts are that although they are cheap, they suffer from poor stability and selectivity, low activity, and a low conversion rate. An in-depth study of the reaction mechanisms of the catalytic process would be very helpful. The interaction and collaboration between active components and supports, in other words, the multi-component composite catalysts may be prepared to further improve the catalysts' performance. Optimizing the formula and loading process of active components with a well-established computational approach and artificial intelligence is challenging and exciting. The traditional production process of VCM adopts the fixed bed reaction technology, which is well established and mature; however, the catalysts in this process suffer large loss, easily get pulverized, and suffer poor heat transfer, which limits the catalytic performance of the catalysts.

With continuing efforts and deeper understanding of the catalytic mechanism, the design and development of non-mercury catalysts with satisfactory performance is viable. The industrial application of mercury-free acetylene hydrochlorination catalysts is expected to be realized in the near future.

Funding: This work was financially supported by UESTC Talent Startup Funds (A1098 53102360 1208), National Natural Science Foundation of China $(21464015,21472235)$, and Xinjiang Tianshan Talents Program (2018xgytsyc 2-3). 
Conflicts of Interest: The authors declare no conflict of interest.

\section{References}

1. Xu, H.; Luo, G.H. Green production of PVC from laboratory to industrialization: State-of-the-art review of heterogeneous non-mercury catalysts for acetylene hydrochlorination. J. Ind. Eng. Chem. 2018, 65, 13-25. [CrossRef]

2. He, W.; Zhu, G.Q.; Gao, Y.; Wu, H.; Fang, Z.; Guo, K. Green plasticizers derived from epoxidized soybean oil for poly (vinyl chloride): Continuous synthesis and evaluation in PVC films. Chem. Eng. J. 2020, 380, 122532. [CrossRef]

3. Shi, D.Z.; Hu, R.S.; Zhou, Q.H.; Yang, L.R. Catalytic activities of supported perovskite promoter catalysts $\mathrm{La}_{2} \mathrm{NiMnO}_{6}-\mathrm{CuCl}_{2} / \gamma-\mathrm{Al}_{2} \mathrm{O}_{3}$ and $\mathrm{La}_{1.7} \mathrm{~K}_{0.3} \mathrm{NiMnO}_{6}-\mathrm{CuCl}_{2} / \gamma-\mathrm{Al}_{2} \mathrm{O}_{3}$ for ethane oxychlorination. Chem. Eng. J. 2016, 288, 588-595. [CrossRef]

4. Ye, L.; Duan, X.P.; Wu, S.; Wu, T.S.; Zhao, Y.X.; Robertson, A.W.; Chou, H.L.; Zheng, J.W.; Ayvali, T.; Day, S.; et al. Self-regeneration of $\mathrm{Au} / \mathrm{CeO}_{2}$ based catalysts with enhanced activity and ultra-stability for acetylene hydrochlorination. Nat. Commun. 2019, 10, 914. [CrossRef] [PubMed]

5. Conte, M.; Carley, A.F.; Heirene, C.; Willock, D.J.; Johnston, P.; Herzing, A.A.; Kiely, C.J.; Hutchings, G.J. Hydrochlorination of acetylene using a supported gold catalyst: A study of the reaction mechanism. J. Catal. 2007, 250, 231-239. [CrossRef]

6. Zhang, J.L.; Liu, N.; Li, W.; Dai, B. Progress on cleaner production of vinyl chloride monomers over non-mercury catalysts. Front. Chem. Sci. Eng. 2011, 5, 514-520. [CrossRef]

7. Malta, G.; Freakley, S.J.; Kondrat, S.A.; Hutchings, G.J. Acetylene hydrochlorination using Au/carbon: A journey towards single site catalysis. Chem. Commun. 2017, 53, 11733-11746. [CrossRef]

8. Johnston, P.; Carthey, N.; Hutchings, G.J. Discovery, development, and commercialization of gold catalysts for acetylene hydrochlorination. J. Am. Chem. Soc. 2015, 137, 14548-14557. [CrossRef]

9. Ren, W.; Duan, L.; Zhu, Z.W.; Du, W.; An, Z.Y.; Xu, L.J.; Zhang, C.; Zhuo, Y.Q.; Chen, C.H. Mercury transformation and distribution across a polyvinyl chloride (PVC) production line in China. Environ. Sci. Technol. 2014, 48, 2321-2327. [CrossRef]

10. Hutchings, G.J. Gold catalysis in chemical processing. Catal. Today 2002, 72, 11-17. [CrossRef]

11. Zhou, K.; Jia, J.C.; Li, X.G.; Pang, X.D.; Li, C.H.; Zhou, J.; Luo, G.H.; Wei, F. Continuous vinyl chloride monomer production by acetylene hydrochlorination on $\mathrm{Hg}$-free bismuth catalyst: From lab-scale catalyst characterization, catalytic evaluation to a pilot-scale trial by circulating regeneration in coupled fluidized beds. Fuel Process. Technol. 2013, 108, 12-18. [CrossRef]

12. Smith, D.M.; Walsh, P.M.; Slager, T.L. Studies of silica-supported metal chloride catalysts for the vapor-phase hydrochlorination of acetylene. J. Catal. 1968, 11, 113-130. [CrossRef]

13. Shinoda, K. The vapor-phase hidrochlorination of acetylene over metal chlorides supported on activated carbon. Chem. Lett. 1975, 4, 219-220. [CrossRef]

14. Hutchings, G.J. Vapor phase hydrochlorination of acetylene: Correlation of catalytic activity of supported metal chloride catalysts. J. Catal. 1985, 96, 292-295. [CrossRef]

15. Nkosi, B.; Coville, N.J.; Hutchings, G.J. Reactivation of a supported gold catalyst for acetylene hydrochlorination. J. Chem. Soc. Chem. Commun. 1988, 71-72. [CrossRef]

16. Nkosi, B.; Coville, N.J.; Hutchings, G.J. Vapour phase hydrochlorination of acetylene with group VIII and IB metal chloride catalysts. Appl. Catal. 1988, 43, 33-39. [CrossRef]

17. Zhou, K.; Wang, W.; Zhao, Z.; Luo, G.; Miller, J.T.; Wong, M.S.; Wei, F. Synergistic gold-bismuth catalysis for non-mercury hydrochlorination of acetylene to vinyl chloride monomer. ACS Catal. 2014, 4, 3112-3116. [CrossRef]

18. Hashmi, A.S.K. Homogeneous gold catalysts and alkynes: A successful liaison. Gold Bull. 2003, 36, 3-9. [CrossRef]

19. Schmidbaur, H. Gold: Progress in Chemistry, Biochemistry, and Technology; John Wiley \& Sons Inc: New York, NY, USA, 1999; p. 894.

20. Krasnyakova, T.V.; Zhikharev, I.V.; Mitchenko, R.S.; Burkhovetski, V.I.; Korduban, A.M.; Kryshchuk, T.V.; Mitchenko, S.A. Acetylene catalytic hydrochlorination over mechanically pre-activated $\mathrm{K}_{2} \mathrm{PdCl}_{4}$ salt: A study of the reaction mechanism. J. Catal. 2012, 288, 33-43. [CrossRef] 
21. Mitchenko, S.A.; Ananikov, V.P.; Beletskaya, I.P. Mechanoactivation of acetylene hydrochlorination in the presence of $\mathrm{K}_{2} \mathrm{PtCl}_{6}$. Zhurnal. Org. Khimii. 1998, 34, 1859-1860. [CrossRef]

22. Mitchenko, S.A. Acetylene hydrochlorination by gaseous hydrogen chloride on the surface of mechanically activated $\mathrm{K}_{2} \mathrm{PtCl}_{6}$ salt. Kinet. Catal. 1998, 39, 859-862. [CrossRef]

23. Mitchenko, S.A.; Krasnyakova, T.V.; Mitchenko, R.S.; Korduban, A.N. Acetylene catalytic hydrochlorination over powder catalyst prepared by pre-milling of $\mathrm{K}_{2} \mathrm{PtCl}_{4}$ salt. J. Mol. Catal. A-Chem. 2007, 275, 101-108. [CrossRef]

24. Conte, M.; Davies, C.J.; Morgan, D.J.; Carley, A.F.; Johnston, P.; Hutchings, G.J. Characterization of Au ${ }^{3+}$ species in $\mathrm{Au} / \mathrm{C}$ catalysts for the hydrochlorination reaction of acetylene. Catal. Lett. 2014, 144, 1-8. [CrossRef]

25. Liu, X.; Conte, M.; Elias, D.; Lu, L.; Morgan, D.J.; Freakley, S.J.; Johnston, P.; Kiely, C.J.; Hutchings, G.J. Investigation of the active species in the carbon-supported gold catalyst for acetylene hydrochlorination. Catal. Sci. Technol. 2016, 6, 5144-5153. [CrossRef]

26. Nkosi, B.; Adams, M.D.; Coville, N.J.; Hutchings, G.J. Hydrochlorination of acetylene using carbon-supported gold catalysts: A study of catalyst reactivation. J. Catal. 1991, 128, 378-386. [CrossRef]

27. Conte, M.; Davies, C.J.; Morgan, D.J.; Davies, T.E.; Elias, D.J.; Carley, A.F.; Johnston, P.; Hutchings, G.J. Aqua regia activated $\mathrm{Au} / \mathrm{C}$ catalysts for the hydrochlorination of acetylene. J. Catal. 2013, 297, 128-136. [CrossRef]

28. Zhao, J.; Wang, B.L.; Xu, X.L.; Yu, Y.; Di, S.X.; Xu, H.; Zhai, Y.Y.; He, H.H.; Guo, L.L.; Pan, Z.Y.; et al. Alternative solvent to aqua regia to activate $\mathrm{Au} / \mathrm{AC}$ catalysts for the hydrochlorination of acetylene. J. Catal. 2017, 350, 149-158. [CrossRef]

29. Huang, C.F.; Zhu, M.Y.; Kang, L.H.; Dai, B. A novel high-stability Au(III)/schiff-based catalyst for acetylene hydrochlorination reaction. Catal. Commun. 2014, 54, 61-65. [CrossRef]

30. Chao, S.L.; Guan, Q.X.; Li, W. Study of the active site for acetylene hydrochlorination in $\mathrm{AuCl}_{3} / \mathrm{C}$ catalysts. J. Catal. 2015, 330, 273-279. [CrossRef]

31. Zhang, C.M.; Zhang, H.Y.; Man, B.C.; Li, X.; Dai, H.; Zhang, J.L. Hydrochlorination of acetylene catalyzed by activated carbon supported highly dispersed gold nanoparticles. Appl. Catal. A Gen. 2018, 566, 15-24. [CrossRef]

32. Wittanadecha, W.; Laosiripojana, N.; Ketcong, A.; Ningnuek, N.; Praserthdam, P.; Monnier, J.R.; Assabumrungrat, S. Preparation of $\mathrm{Au} / \mathrm{C}$ catalysts using microwave-assisted and ultrasonic-assisted methods for acetylene hydrochlorination. Appl. Catal. A Gen. 2014, 475, 292-296. [CrossRef]

33. Tian, X.H.; Hong, G.T.; Jiang, B.B.; Lu, F.P.; Liao, Z.W.; Wang, J.D.; Yang, Y.R. Efficient $\mathrm{Au}^{0} / \mathrm{C}$ catalyst synthesized by a new method for acetylene hydrochlorination. RSC Adv. 2015, 5, 46366-46371. [CrossRef]

34. Conte, M.; Carley, A.F.; Attard, G.; Herzing, A.A.; Kiely, C.J.; Hutchings, G.J. Hydrochlorination of acetylene using supported bimetallic Au-based catalysts. J. Catal. 2008, 257, 190-198. [CrossRef]

35. Zhu, M.Y.; Wang, Q.Q.; Chen, K.; Wang, Y.; Huang, C.F.; Dai, H.; Yu, F.; Kang, L.H.; Dai, B. Development of a heterogeneous non-mercury catalyst for acetylene hydrochlorination. ACS Catal. 2015, 5, 5306-5316. [CrossRef]

36. Li, G.B.; Li, W.; Zhang, J.L. Non-mercury catalytic acetylene hydrochlorination over activated carbon-supported Au catalysts promoted by $\mathrm{CeO}_{2}$. Catal. Sci. Technol. 2016, 6, 1821-1828. [CrossRef]

37. Ke, J.H.; Zhao, Y.X.; Yin, Y.; Chen, K.; Duan, X.P.; Ye, L.M.; Yuan, Y.Z. Yttrium chloride-modified Au/AC catalysts for acetylene hydrochlorination with improved activity and stability. J. Rare Earths 2017, 35, 1083-1091. [CrossRef]

38. Dong, Y.Z.; Zhang, H.Y.; Li, W.; Sun, M.X.; Guo, C.L.; Zhang, J.L. Bimetallic Au-Sn/AC catalysts for acetylene hydrochlorination. J. Ind. Eng. Chem. 2016, 35, 177-184. [CrossRef]

39. Zhao, J.; Yu, Y.; Xu, X.L.; Di, S.X.; Wang, B.L.; Xu, H.; Ni, J.; Guo, L.L.; Pan, Z.Y.; Li, X.N. Stabilizing Au(III) in supported-ionic-liquid-phase (SILP) catalyst using $\mathrm{CuCl}_{2}$ via a redox mechanism. Appl. Catal. B Environ. 2017, 206, 175-183. [CrossRef]

40. Du, Y.F.; Hu, R.S.; Jia, Y.; Zhou, Q.H.; Meng, W.W.; Yang, J. $\mathrm{CuCl}_{2}$ promoted low-gold-content Au/C catalyst for acetylene hydrochlorination prepared by ultrasonic-assisted impregnation. J. Ind. Eng. Chem. 2016, 37, 32-41. [CrossRef]

41. Zhao, J.G.; Zeng, J.J.; Cheng, X.G.; Wang, L.; Yang, H.H.; Shen, B.X. An Au-Cu bimetal catalyst for acetylene hydrochlorination with renewable $\gamma-\mathrm{Al}_{2} \mathrm{O}_{3}$ as the support. RSC Adv. 2015, 5, 16727-16734. [CrossRef]

42. Wang, L.; Shen, B.X.; Zhao, J.G.; Bi, X.T. Trimetallic Au-Cu-K/AC for acetylene hydrochlorination. Can. J. Chem. Eng. 2017, 95, 1069-1075. [CrossRef] 
43. Zhang, H.Y.; Dai, B.; Li, W.; Wang, X.G.; Zhang, J.L.; Zhu, M.Y.; Gu, J.J. Non-mercury catalytic acetylene hydrochlorination over spherical activated-carbon-supported $\mathrm{Au}-\mathrm{Co}(\mathrm{III})-\mathrm{Cu}(\mathrm{II})$ catalysts. J. Catal. 2014, 316, 141-148. [CrossRef]

44. Li, G.B.; Li, W.; Zhang, J.L.; Zhang, W.; Zhou, H.; Si, C.L. The effect of N-doping in activated carbon-supported $\mathrm{Au}-\mathrm{Sr}$ catalysts for acetylene hydrochlorination to vinyl chloride. ChemistrySelect 2018, 3, 3561-3569. [CrossRef]

45. Li, G.B.; Li, W.; Zhang, J.L. Strontium promoted activated carbon-supported gold catalysts for non-mercury catalytic acetylene hydrochlorination. Catal. Sci. Technol. 2016, 6, 3230-3237. [CrossRef]

46. Zhang, H.Y.; Li, W.; Li, X.Q.; Zhao, W.; Gu, J.J.; Qi, X.Y.; Dong, Y.Z.; Dai, B.; Zhang, J.L. Non-mercury catalytic acetylene hydrochlorination over bimetallic Au-Ba(ii)/AC catalysts. Catal. Sci. Technol. 2015, 5, 1870-1877. [CrossRef]

47. Zhao, J.; Xu, J.T.; Xu, J.H.; Ni, J.; Zhang, T.T.; Xu, X.L.; Li, X.N. Activated-carbon-supported gold-cesium(I) as highly effective catalysts for hydrochlorination of acetylene to vinyl chloride. ChemPlusChem 2015, 80, 196-201. [CrossRef]

48. Zhao, J.; Zhang, T.T.; Di, X.X.; Xu, J.T.; Xu, J.; Feng, F.; Ni, J.; Li, X.N. Nitrogen-modified activated carbon supported bimetallic gold-cesium(i) as highly active and stable catalyst for the hydrochlorination of acetylene. RSC Adv. 2015, 5, 6925-6931. [CrossRef]

49. Zhao, J.; Zhang, T.T.; Di, X.X.; Xu, J.T.; Gu, S.C.; Zhang, Q.F.; Ni, J.; Li, X.N. Activated carbon supported ternary gold-cesium(i)-indium(iii) catalyst for the hydrochlorination of acetylene. Catal. Sci. Technol. 2015, 5, 4973-4984. [CrossRef]

50. Zhao, J.; Cheng, X.; Wang, L.; Ren, R.; Zeng, J.; Yang, H.; Shen, B. Free-mercury catalytic acetylene hydrochlorination over bimetallic $\mathrm{Au}-\mathrm{Bi} / \gamma-\mathrm{Al}_{2} \mathrm{O}_{3}$ :A low gold content catalyst. Catal. Lett. 2014, 144, 2191-2197. [CrossRef]

51. Huang, C.F.; Zhu, M.Y.; Kang, L.H.; Li, X.Y.; Dai, B. Active carbon supported $\mathrm{TiO}_{2}-\mathrm{AuCl}_{3} / \mathrm{AC}$ catalyst with excellent stability for acetylene hydrochlorination reaction. Chem. Eng. J. 2014, 242, 69-75. [CrossRef]

52. Pu, Y.F.; Zhang, J.L.; Wang, X.; Zhang, H.Y.; Yu, L.; Dong, Y.Z.; Li, W. Bimetallic Au-Ni/CSs catalysts for acetylene hydrochlorination. Catal. Sci. Technol. 2014, 4, 4426-4432. [CrossRef]

53. Zhang, H.Y.; Dai, B.; Wang, X.G.; Li, W.; Han, Y.; Gu, J.J.; Zhang, J.L. Non-mercury catalytic acetylene hydrochlorination over bimetallic $\mathrm{Au}-\mathrm{Co}(\mathrm{iii}) / \mathrm{SAC}$ catalysts for vinyl chloride monomer production. Green Chem. 2013, 15, 829-836. [CrossRef]

54. Zhang, H.Y.; Dai, B.; Wang, X.G.; Xu, L.L.; Zhu, M.Y. Hydrochlorination of acetylene to vinyl chloride monomer over bimetallic Au-La/SAC catalysts. J. Ind. Eng. Chem. 2012, 18, 49-54. [CrossRef]

55. Goguet, A.; Hardacre, C.; Harvey, I.; Narasimharao, K.; Saih, Y.; Sa, J. Increased dispersion of supported gold during methanol carbonylation conditions. J. Am. Chem. Soc. 2009, 131, 6973-6975. [CrossRef]

56. Zhong, J.W.; Xu, Y.P.; Liu, Z.M. Heterogeneous non-mercury catalysts for acetylene hydrochlorination: Progress, challenges, and opportunities. Green Chem. 2018, 20, 2412-2427. [CrossRef]

57. Zhou, K.; Jia, J.C.; Li, C.H.; Xu, H.; Zhou, J.; Luo, G.H.; Wei, F. A low content Au-based catalyst for hydrochlorination of $\mathrm{C}_{2} \mathrm{H}_{2}$ and its industrial scale-up for future PVC processes. Green Chem. 2015, 17, 356-364. [CrossRef]

58. Li, X.B.; Wang, H.Y.; Yang, X.D.; Zhu, Z.H.; Tang, Y.J. Size dependence of the structures and energetic and electronic properties of gold clusters. J. Chem. Phys. 2007, 126, 084505. [CrossRef]

59. Li, Y.F.; Mao, A.J.; Li, Y.; Kuang, X.Y. Density functional study on size-dependent structures, stabilities, electronic and magnetic properties of $\mathrm{Au}_{\mathrm{n}} \mathrm{M}(\mathrm{M}=\mathrm{Al}$ and $\mathrm{Si}, \mathrm{n}=1-9)$ clusters: Comparison with pure gold clusters. J. Mol. Model. 2012, 18, 3061-3072. [CrossRef]

60. Bürgel, C.; Reilly, N.M.; Johnson, G.E.; Mitrić, R.; Kimble, M.L.; Castleman, A.W.; Bonačić-Koutecký, V. Influence of charge state on the mechanism of co oxidation on gold clusters. J. Am. Chem. Soc. 2008, 130, 1694-1698. [CrossRef]

61. Socaciu, L.D.; Hagen, J.; Bernhardt, T.M.; Wöste, L.; Heiz, U.; Häkkinen, H.; Landman, U. Catalytic co oxidation by free $\mathrm{Au}_{2}{ }^{-}$: Experiment and theory. J. Am. Chem. Soc. 2003, 125, 10437-10445. [CrossRef]

62. Gao, M.; Lyalin, A.; Taketsugu, T. Role of the support effects on the catalytic activity of gold clusters: A density functional theory study. Catalysts 2011, 1, 18-39. [CrossRef]

63. Spivey, K.; Williams, J.I.; Wang, L. Structures of undecagold clusters: Ligand effect. Chem. Phys. Lett. 2006, 432, 163-166. [CrossRef] 
64. Zhao, Y.; Zhao, F.; Kang, L.H. Catalysis of the acetylene hydrochlorination reaction by Si-doped Au clusters: A DFT study. J. Mol. Model. 2018, 24, 61. [CrossRef] [PubMed]

65. Xu, H.; Zhou, K.; Si, J.; Li, C.; Luo, G. A ligand coordination approach for high reaction stability of an Au-Cu bimetallic carbon-based catalyst in the acetylene hydrochlorination process. Catal. Sci. Technol. 2016, 6, 1357-1366. [CrossRef]

66. Li, X.; Zhu, M.; Dai, B. AuCl 3 on polypyrrole-modified carbon nanotubes as acetylene hydrochlorination catalysts. Appl. Catal. B Environ. 2013, 142, 234-240. [CrossRef]

67. Chen, K.; Kang, L.H.; Zhu, M.Y.; Dai, B. Mesoporous carbon with controllable pore sizes as a support of the $\mathrm{AuCl} 3$ catalyst for acetylene hydrochlorination. Catal. Sci. Technol. 2015, 5, 1035-1040. [CrossRef]

68. Jia, Y.; Hu, R.S.; Zhou, Q.H.; Wang, H.Y.; Gao, X.; Zhang, J. Boron-modified activated carbon supporting low-content Au-based catalysts for acetylene hydrochlorination. J. Catal. 2017, 348, 223-232. [CrossRef]

69. Li, X.Y.; Wang, Y.; Kang, L.H.; Zhu, M.Y.; Dai, B. A novel, non-metallic graphitic carbon nitride catalyst for acetylene hydrochlorination. J. Catal. 2014, 311, 288-294. [CrossRef]

70. Yang, Y.; Lan, G.J.; Wang, X.L.; Li, Y. Direct synthesis of nitrogen-doped mesoporous carbons for acetylene hydrochlorination. Chin. J. Catal. 2016, 37, 1242-1248. [CrossRef]

71. Zhao, J.; Xu, J.; Xu, J.; Zhang, T.; Di, X.; Ni, J.; Li, X. Enhancement of Au/AC acetylene hydrochlorination catalyst activity and stability via nitrogen-modified activated carbon support. Chem. Eng. J. 2015, 262, 1152-1160. [CrossRef]

72. Zhao, J.; Gu, S.C.; Xu, X.L.; Zhang, T.T.; Yu, Y.; Di, X.X.; Ni, J.; Pan, Z.Y.; Li, X.N. Supported ionic-liquid-phase-stabilized Au(iii) catalyst for acetylene hydrochlorination. Catal. Sci. Technol. 2016, 6, 3263-3270. [CrossRef]

73. Tian, X.H.; Hong, G.T.; Liu, Y.; Jiang, B.B.; Yang, Y.R. Catalytic performance of AuIII supported on $\mathrm{SiO}_{2}$ modified activated carbon. RSC Adv. 2014, 4, 36316-36324. [CrossRef]

74. Dai, B.; Li, X.; Zhang, J.; Yu, F.; Zhu, M. Application of mesoporous carbon nitride as a support for an Au catalyst for acetylene hydrochlorination. Chem. Eng. Sci. 2015, 135, 472-478. [CrossRef]

75. Wang, Y.; Zhu, M.; Kang, L.; Dai, B. Neutral Aun ( $=3-10)$ clusters catalyze acetylene hydrochlorination: A density functional theory study. RSC Adv. 2014, 4, 38466-38473. [CrossRef]

76. Gong, W.Q.; Zhao, F.; Kang, L.H. Novel nitrogen-doped Au-embedded graphene single-atom catalysts for acetylene hydrochlorination: A density functional theory study. Comput. Theor. Chem. 2018, 1130, 83-89. [CrossRef]

77. Zhang, J.L.; He, Z.H.; Li, W.; Han, Y. Deactivation mechanism of $\mathrm{AuCl}_{3}$ catalyst in acetylene hydrochlorination reaction: A DFT study. RSC Adv. 2012, 2, 4814-4821. [CrossRef]

78. Nkosi, B.; Coville, N.J.; Hutchings, G.J.; Adams, M.D.; Friedl, J.; Wagner, F.E. Hydrochlorination of acetylene using gold catalysts: A study of catalyst deactivation. J. Catal. 1991, 128, 366-377. [CrossRef]

79. Conte, M.; Davies, C.J.; Morgan, D.J.; Davies, T.E.; Carley, A.F.; Johnston, P.; Hutchings, G.J. Modifications of the metal and support during the deactivation and regeneration of $\mathrm{Au} / \mathrm{C}$ catalysts for the hydrochlorination of acetylene. Catal. Sci. Technol. 2013, 3, 128-134. [CrossRef]

80. Hashmi, A.S.K.; Blanco, M.C.; Fischer, D.; Bats, J.W. Gold catalysis: Evidence for the in-situ reduction of gold(iii) during the cyclization of allenyl carbinols. Eur. J. Org. Chem. 2006, 2006, 1387-1389. [CrossRef]

81. Conte, M.; Carley, A.F.; Hutchings, G.J. Reactivation of a carbon-supported gold catalyst for the hydrochlorination of acetylene. Catal. Lett. 2008, 124, 165-167. [CrossRef]

82. Dai, B.; Wang, Q.Q.; Yu, F.; Zhu, M.Y. Effect of Au nano-particle aggregation on the deactivation of the $\mathrm{AuCl}_{3} / \mathrm{AC}$ catalyst for acetylene hydrochlorination. Sci Rep 2015, 5, 10553. [CrossRef]

83. Malta, G.; Kondrat, S.A.; Freakley, S.J.; Davies, C.J.; Dawson, S.; Liu, X.; Lu, L.; Dymkowski, K.; Fernandez-Alonso, F.; Mukhopadhyay, S.; et al. Deactivation of a single-site gold-on-carbon acetylene hydrochlorination catalyst: An X-ray absorption and inelastic neutron scattering study. ACS Catal. 2018, 8, 8493-8505. [CrossRef]

84. Zhu, M.Y.; Kang, L.H.; Su, Y.; Zhang, S.Z.; Dai, B. $\mathrm{MCl}_{\mathrm{x}}(\mathrm{M}=\mathrm{Hg}$, $\mathrm{Au}, \mathrm{Ru} ; \mathrm{x}=2$, 3) catalyzed hydrochlorination of acetylene-A density functional theory study. Can. J. Chem. 2013, 91, 120-125. [CrossRef]

85. Li, H.; Wu, B.T.; Wang, F.M.; Zhang, X.B. Efficient and stable Ru(III)/choline chloride catalyst system with low Ru content for non-mercury acetylene hydrochlorination. Chin. J. Catal. 2018, 39, 1770-1781. [CrossRef] 
86. Li, X.; Zhang, H.; Man, B.; Zhang, C.; Dai, H.; Dai, B.; Zhang, J. Synthesis of vinyl chloride monomer over carbon-supported tris-(triphenylphosphine) ruthenium dichloride catalysts. Catalysts 2018, 8, 276. [CrossRef]

87. Wang, X.; Lan, G.; Liu, H.; Zhu, Y.; Li, Y. Effect of acidity and ruthenium species on catalytic performance of ruthenium catalysts for acetylene hydrochlorination. Catal. Sci. Technol. 2018, 8, 6143-6149. [CrossRef]

88. Gu, J.; Gao, Y.; Zhang, J.; Li, W.; Dong, Y.; Han, Y. Hydrochlorination of acetylene catalyzed by an activated carbon-supported ammonium hexachlororuthenate complex. Catalysts 2017, 7, 17. [CrossRef]

89. Li, X.; Zhang, H.; Man, B.; Hou, L.; Zhang, C.; Dai, H.; Zhu, M.; Dai, B.; Dong, Y.; Zhang, J. Activated carbon-supported tetrapropylammonium perruthenate catalysts for acetylene hydrochlorination. Catalysts 2017, 7, 311. [CrossRef]

90. Zhao, W.; Li, W.; Zhang, J. Ru/N-AC catalyst to produce vinyl chloride from acetylene and 1,2-dichloroethane. Catal. Sci. Technol. 2016, 6, 1402-1409. [CrossRef]

91. Zhang, J.L.; Sheng, W.; Guo, C.L.; Li, W. Acetylene hydrochlorination over bimetallic Ru-based catalysts. RSC Adv. 2013, 3, 21062-21068. [CrossRef]

92. Pu, Y.F.; Zhang, J.L.; Yu, L.; Jin, Y.H.; Li, W. Active ruthenium species in acetylene hydrochlorination. Appl. Catal. A Gen. 2014, 488, 28-36. [CrossRef]

93. Zhang, H.Y.; Li, W.; Jin, Y.H.; Sheng, W.; Hu, M.C.; Wang, X.Q.; Zhang, J.L. Ru-Co(III)-Cu(II)/SAC catalyst for acetylene hydrochlorination. Appl. Catal. B-Environ. 2016, 189, 56-64. [CrossRef]

94. Li, Y.; Dong, Y.Z.; Li, W.; Han, Y.; Zhang, J.L. Improvement of imidazolium-based ionic liquids on the activity of ruthenium catalyst for acetylene hydrochlorination. Mol. Catal. 2017, 443, 220-227. [CrossRef]

95. Mitchenko, S.A.; Khomutov, E.V.; Shubin, A.A.; Shul'ga, Y.M. Mechanochemical activation of $\mathrm{K}_{2} \mathrm{PtCl}_{6}$ : Heterogeneous catalyst for gas-phase hydrochlorination of acetylene. Theor. Exp. Chem. 2003, 39, 255-258. [CrossRef]

96. Mitchenko, S.A.; Khomutov, E.V.; Shubin, A.A.; Shul'ga, Y.M. Catalytic hydrochlorination of acetylene by gaseous $\mathrm{HCl}$ on the surface of mechanically pre-activated $\mathrm{K}_{2} \mathrm{PtCl}_{6}$ salt. J. Mol. Catal. A-Chem. 2004, 212, 345-352. [CrossRef]

97. Mitchenko, S.A.; Krasnyakova, T.V. Acetylene hydrochlorination over mechanically activated $\mathrm{K}_{2} \mathrm{MCl}_{4}$ $(\mathrm{M}=\mathrm{Pt}, \mathrm{Pd})$ and $\mathrm{K}_{2} \mathrm{PtCl}_{6}$ catalysts: The $\mathrm{HCl} / \mathrm{DCl}$ kinetic isotope effect and reaction mechanisms. Kinet. Catal. 2014, 55, 722-728. [CrossRef]

98. Strebelle, M.; Devos, A. Catalytic Hydrochlorination System and Process for the Manufacture of Vinyl Chloride from Acetylene and Hydrogen Chloride in the Presence of this Catalytic System. U.S. Patent NO. 5,254,777, 17 October 1993.

99. Wang, L.; Wang, F.; Wang, J. Enhanced stability of hydrochlorination of acetylene using polyaniline-modified $\mathrm{Pd} / \mathrm{HY}$ catalysts. Catal. Commun. 2016, 74, 55-59. [CrossRef]

100. Wang, L.; Wang, F.; Wang, J. Effect of $\mathrm{K}$ promoter on the stability of Pd/NFY catalysts for acetylene hydrochlorination. Catal. Commun. 2016, 83, 9-13. [CrossRef]

101. Wang, L.; Wang, F.; Wang, J.D. Catalytic properties of $\mathrm{Pd} / \mathrm{HY}$ catalysts modified with $\mathrm{NH}_{4} \mathrm{~F}$ for acetylene hydrochlorination. Catal. Commun. 2015, 65, 41-45. [CrossRef]

102. Wang, L.; Wang, F.; Wang, J.D.; Tang, X.L.; Zhao, Y.L.; Yang, D.; Jia, F.M.; Hao, T. Hydrochlorination of acetylene to vinyl chloride over Pd supported on zeolite Y. React. Kinet. Mech. Catal. 2013, 110, 187-194. [CrossRef]

103. Song, Q.L.; Wang, S.J.; Shen, B.X.; Zhao, J.G. Palladium-based catalysts for the hydrochlorination of acetylene: Reasons for deactivation and its regeneration. Pet. Sci. Technol. 2010, 28, 1825-1833. [CrossRef]

104. Li, P.; Ding, M.Z.; He, L.M.; Tie, K.; Ma, H.; Pan, X.L.; Bao, X.H. The activity and stability of $\mathrm{PdCl} 2 / \mathrm{C}-\mathrm{N}$ catalyst for acetylene hydrochlorination. Sci. China Chem. 2018, 61, 444-448. [CrossRef]

105. Yang, L.F.; Yang, Q.W.; Hu, J.Y.; Bao, Z.B.; Su, B.G.; Zhang, Z.G.; Ren, Q.L.; Xing, H.B. Metal nanoparticles in ionic liquid-cosolvent biphasic systems as active catalysts for acetylene hydrochlorination. Aiche. J. 2018, 64, 2536-2544. [CrossRef]

106. Zhao, J.; Yue, Y.X.; Sheng, G.F.; Wang, B.L.; Lai, H.X.; Di, S.X.; Zhai, Y.Y.; Guo, L.L.; Li, X.N. Supported ionic liquid-palladium catalyst for the highly effective hydrochlorination of acetylene. Chem. Eng. J. 2019, 360, 38-46. [CrossRef]

107. Perkins, G.A. Preparation of Vinyl Chloride. U.S. Patent No. 1,934,324, 7 November 1933. 
108. Zhai, Y.Y.; Zhao, J.; Di, X.X.; Di, S.X.; Wang, B.L.; Yue, Y.X.; Sheng, G.F.; Lai, H.X.; Guo, L.L.; Wang, H.; et al. Carbon-supported perovskite-like $\mathrm{CsCuCl}_{3}$ nanoparticles: A highly active and cost-effective heterogeneous catalyst for the hydrochlorination of acetylene to vinyl chloride. Catal. Sci. Technol. 2018, 8, 2901-2908. [CrossRef]

109. Zhao, W.L.; Zhu, M.Y.; Dai, B. The preparation of $\mathrm{Cu}-\mathrm{g}-\mathrm{C}_{3} \mathrm{~N}_{4} / \mathrm{AC}$ catalyst for acetylene hydrochlorination. Catalysts 2016, 6, 193. [CrossRef]

110. Li, H.; Wang, F.M.; Cai, W.F.; Zhang, J.L.; Zhang, X.B. Hydrochlorination of acetylene using supported phosphorus-doped Cu-based catalysts. Catal. Sci. Technol. 2015, 5, 5174-5184. [CrossRef]

111. Xu, J.T.; Zhao, J.; Zhang, T.T.; Di, X.X.; Gu, S.C.; Ni, J.; Li, X.N. Ultra-low Ru-promoted CuCl $\mathrm{Cu}_{2}$ highly active catalyst for the hydrochlorination of acetylene. RSC Adv. 2015, 5, 38159-38163. [CrossRef]

112. Zhou, K.; Si, J.K.; Jia, J.C.; Huang, J.Q.; Zhou, J.; Luo, G.H.; Wei, F. Reactivity enhancement of N-CNTs in green catalysis of $\mathrm{C}_{2} \mathrm{H}_{2}$ hydrochlorination by a Cu catalyst. RSC Adv. 2014, 4, 7766-7769. [CrossRef]

113. Hu, D.; Wang, L.; Wang, F.; Wang, J.D. Active carbon supported S-promoted Bi catalysts for acetylene hydrochlorination reaction. Chin. Chem. Lett. 2018, 29, 1413-1416. [CrossRef]

114. Dai, H.; Zhu, M.Y.; Zhang, H.Y.; Yu, F.; Wang, C.; Dai, B. Activated carbon supported Mo-Ti-N binary transition metal nitride as catalyst for acetylene hydrochlorination. Catalysts 2017, 7, 200. [CrossRef]

115. Dai, H.; Zhu, M.Y.; Zhang, H.Y.; Yu, F.; Wang, C.; Dai, B. Activated carbon supported VN, $\mathrm{Mo}_{2} \mathrm{~N}$, and $\mathrm{W}_{2} \mathrm{~N}$ as catalysts for acetylene hydrochlorination. J. Ind. Eng. Chem. 2017, 50, 72-78. [CrossRef]

116. Dai, H.; Zhu, M.Y.; Zhao, D.; Yu, F.; Dai, B. Effective catalytic performance of plasma-enhanced $W_{2} N / A C$ as catalysts for acetylene hydrochlorination. Top. Catal. 2017, 60, 1016-1023. [CrossRef]

117. Zhao, W.L.; Zhu, M.Y.; Dai, B. Cobalt-nitrogen-activated carbon as catalyst in acetylene hydrochlorination. Catal. Commun. 2017, 98, 22-25. [CrossRef]

118. Lan, G.; Qiu, Y.; Fan, J.; Wang, X.; Tang, H.; Han, W.; Liu, H.; Liu, H.; Song, S.; Li, Y. Defective graphene@diamond hybrid nanocarbon material as an effective and stable metal-free catalyst for acetylene hydrochlorination. Catal. Commun. 2019, 55, 1430-1433. [CrossRef]

119. Li, X.; Zhang, J.; Han, Y.; Zhu, M.; Shang, S.; Li, W. MOF-derived various morphologies of N-doped carbon composites for acetylene hydrochlorination. J. Mater. Sci. 2018, 53, 4913-4926. [CrossRef]

120. Dong, X.B.; Chao, S.L.; Wan, F.F.; Guan, Q.X.; Wang, G.C.; Li, W. Sulfur and nitrogen co-doped mesoporous carbon with enhanced performance for acetylene hydrochlorination. J. Catal. 2018, 359, 161-170. [CrossRef]

121. Li, P.; Li, H.B.; Pan, X.L.; Tie, K.; Cui, T.T.; Ding, M.Z.; Bao, X.H. Catalytically active boron nitride in acetylene hydrochlorination. ACS Catal. 2017, 7, 8572-8577. [CrossRef]

122. Li, X.Y.; Zhang, J.L.; Li, W. MOF-derived nitrogen-doped porous carbon as metal-free catalysts for acetylene hydrochlorination. J. Ind. Eng. Chem. 2016, 44, 146-154. [CrossRef]

123. Dai, B.; Chen, K.; Wang, Y.; Kang, L.H.; Zhu, M.Y. Boron and nitrogen doping in graphene for the catalysis of acetylene hydrochlorination. ACS Catal. 2015, 5, 2541-2547. [CrossRef]

124. Li, X.Y.; Pan, X.L.; Bao, X.H. Nitrogen doped carbon catalyzing acetylene conversion to vinyl chloride. J. Energy Chem. 2014, 23, 131-135. [CrossRef]

125. Zhou, K.; Li, B.; Zhang, Q.; Huang, J.Q.; Tian, G.L.; Jia, J.C.; Zhao, M.Q.; Luo, G.H.; Su, D.S.; Wei, F. The catalytic pathways of hydrohalogenation over metal-free nitrogen-doped carbon nanotubes. ChemSusChem 2014, 7, 723-728. [CrossRef]

126. Wang, X.G.; Dai, B.; Wang, Y.; Yu, F. Nitrogen-doped pitch-based spherical active carbon as a nonmetal catalyst for acetylene hydrochlorination. ChemCatChem 2014, 6, 2339-2344. [CrossRef]

127. Qiao, X.L.; Zhou, Z.Q.; Liu, X.Y.; Zhao, C.Y.; Guan, Q.X.; Li, W. Constructing of fragmentary g- $\mathrm{C}_{3} \mathrm{~N}_{4}$ framework with rich nitrogen defects as highly efficient metal-free catalyst for acetylene hydrochlorination. Catal. Sci. Technol. 2019, 9, 3753-3762. [CrossRef]

128. Zhang, C.L.; Kang, L.H.; Zhu, M.Y.; Dai, B. Nitrogen-doped active carbon as a metal-free catalyst for acetylene hydrochlorination. RSC Adv. 2015, 5, 7461-7468. [CrossRef]

129. Zhao, F.; Kang, L.H. The neglected significant role for graphene-based acetylene hydrochlorination catalysts — intrinsic graphene defects. Chem. Sel. 2017, 2, 6016-6022. [CrossRef]

130. Li, X.Y.; Pan, X.L.; Yu, L.; Ren, P.J.; Wu, X.; Sun, L.T.; Jiao, F.; Bao, X.H. Silicon carbide-derived carbon nanocomposite as a substitute for mercury in the catalytic hydrochlorination of acetylene. Nat. Commun. 2014, 5, 7. [CrossRef] [PubMed] 
131. Zhao, F.; Wang, Y.; Zhu, M.Y.; Kang, L.H. C-doped boron nitride fullerene as a novel catalyst for acetylene hydrochlorination: A DFT study. RSC Adv. 2015, 5, 56348-56355. [CrossRef]

132. Li, X.Y.; Li, P.; Pan, X.L.; Ma, H.; Bao, X.H. Deactivation mechanism and regeneration of carbon nanocomposite catalyst for acetylene hydrochlorination. Appl. Catal. B-Environ. 2017, 210, 116-120. [CrossRef]

133. Chao, S.L.; Zou, F.; Wan, F.F.; Dong, X.B.; Wang, Y.L.; Wang, Y.X.; Guan, Q.X.; Wang, G.C.; Li, W. Nitrogen-doped carbon derived from ZIF-8 as a high-performance metal-free catalyst for acetylene hydrochlorination. Sci. Rep. 2017, 7, 39789. [CrossRef]

134. Song, Z.J.; Liu, G.Y.; He, D.W.; Pang, X.D.; Tong, Y.S.; Wu, Y.Q.; Yuan, D.H.; Liu, Z.M.; Xu, Y.P. Acetylene hydrochlorination over 13X zeolite catalysts at high temperature. Green Chem. 2016, 18, 5994-5998. [CrossRef]

135. Li, X.Y.; Nian, Y.; Shang, S.S.; Zhang, H.Y.; Zhang, J.L.; Han, Y.; Li, W. Novel nonmetal catalyst of supported tetraphenylphosphonium bromide for acetylene hydrochlorination. Catal. Sci. Technol. 2019, 9, 188-198. [CrossRef]

136. Wang, B.L.; Lai, H.X.; Yue, Y.X.; Sheng, G.F.; Deng, Y.Q.; He, H.H.; Guo, L.L.; Zhao, J.; Li, X.N. Zeolite supported ionic liquid catalysts for the hydrochlorination of acetylene. Catalysts 2018, 8, 351. [CrossRef]

137. Zhou, X.F.; Xu, S.G.; Liu, Y.L.; Cao, S.K. Mechanistic study on metal-free acetylene hydrochlorination catalyzed by imidazolium-based ionic liquids. Mol. Catal. 2018, 461, 73-79. [CrossRef]

Publisher's Note: MDPI stays neutral with regard to jurisdictional claims in published maps and institutional affiliations.

(C) 2020 by the authors. Licensee MDPI, Basel, Switzerland. This article is an open access article distributed under the terms and conditions of the Creative Commons Attribution (CC BY) license (http://creativecommons.org/licenses/by/4.0/). 